\title{
Neuronal Apoptosis Associated with Morphine Tolerance: Evidence for an Opioid-Induced Neurotoxic Mechanism
}

\author{
Jianren Mao, ${ }^{1}$ Backil Sung, ${ }^{1}$ Ru-Rong $\mathrm{Ji}^{,}{ }^{2}$ and Grewo Lim ${ }^{1}$ \\ ${ }^{1}$ Massachusetts General Hospital Pain Center and ${ }^{2}$ Neural Plasticity Research Group, Department of Anesthesia and \\ Critical Care, Massachusetts General Hospital, Harvard Medical School, Boston, Massachusetts 02114
}

\begin{abstract}
Tolerance to the analgesic effect of an opioid is a pharmacological phenomenon that occurs after its prolonged administration. Activation of the NMDA receptor (NMDAR) has been implicated in the cellular mechanisms of opioid tolerance. However, activation of NMDARs can lead to neurotoxicity under many circumstances. Here we demonstrate that spinal neuronal apoptosis was induced in rats made tolerant to morphine administered through intrathecal boluses or continuous infusion. The apoptotic cells were predominantly located in the superficial spinal cord dorsal horn, and most apoptotic cells also expressed glutamic acid decarboxylase, a key enzyme for the synthesis of the inhibitory neurotransmitter GABA. Consistently, increased nociceptive sensitivity to heat stimulation was observed in these same rats. Mechanistically, the spinal glutamatergic activity modulated morphine-induced neuronal apoptosis, because pharmacological perturbation of the spinal glutamate transporter activity or coadministration of morphine with the NMDAR antagonist (+)-5-methyl-10,11-dihydro-5H-
\end{abstract}

dibenzo [a,d] cyclohepten-5,10-imine maleate affected both morphine tolerance and neuronal apoptosis. At the intracellular level, prolonged morphine administration resulted in an upregulation of the proapoptotic caspase- 3 and Bax proteins but a downregulation of the antiapoptotic $\mathrm{Bcl}-2$ protein in the spinal cord dorsal horn. Furthermore, coadministration with morphine of $\mathrm{N}$-benzyloxycarbonyl-Val-Ala-Asp-fluoromethyl ketone (a pan-caspase inhibitor) or acetyl-aspartyl-glutamyl-valyl-aspart1-aldehyde (a relatively selective caspase-3 inhibitor) blocked morphine-induced neuronal apoptosis. Blockade of the spinal caspase-like activity also partially prevented morphine tolerance and the associated increase in nociceptive sensitivity. These results indicate an opioid-induced neurotoxic consequence regulated by the NMDAR-caspase pathway, a mechanism that may have clinical implications in opioid therapy and substance abuse.

Key words: apoptosis; opioid tolerance; analgesia; NMDA; glutamate transporter; caspase-3; Bax; Bcl-2
Opioids are a class of powerful analgesics that are commonly used in acute and chronic pain management. Prolonged exposure to an opioid results in the development of analgesic tolerance, which significantly hampers the clinical utility of opioids necessitating repeated dose escalation regardless of disease progression. As such, the cellular and molecular mechanisms of opioid tolerance have been a focus of extensive research interest. Over a decade, the NMDA receptor (NMDAR), a subgroup of glutamate receptors, has been implicated in the development of opioid tolerance, particularly $\mu$-opioid tolerance (Marek et al. 1991a,b; Trujillo and Akil, 1991; Elliott et al., 1994; Mao et al., 1994). Although the mechanisms of NMDAR involvement in opioid analgesic tolerance remain unclear, $\mathrm{Ca}^{2+}$-regulated intracellular protein kinase $\mathrm{C}$ (PKC) is likely to be a link in this process (Mao et al., 1994, 1995c; Mayer et al., 1995; Narita et al., 1996, 2001; Zeitz et al., 2002). PKC may directly or indirectly regulate the activity of NMDARs by removing the $\mathrm{Mg}^{2+}$ blockade from the NMDAR$\mathrm{Ca}^{2+}$ channel site (Chen and Huang, 1992; Woolf and Salter, 2000), regulating NMDAR trafficking and gating (Lan et al., 2001), or both. Thus, NMDARs could become involved in the cellular mechanisms of opioid tolerance after prolonged admin-

Received April 12, 2002; revised June 21, 2002; accepted June 21, 2002.

This work was supported by United States Public Health Service Grant RO1 DA08835 to J.M. We thank Leslie Keniston, Joachim Scholz, and the Neural Plasticity Research Group at Massachusetts General Hospital for technical help.

Correspondence should be addressed to Dr. Jianren Mao, Massachusetts General Hospital Pain Center, Suite WACC 324, Massachusetts General Hospital, Harvard Medical School, 15 Parkman Street, Boston, MA 02114. E-mail: jmao@partners.org. Copyright $\odot 2002$ Society for Neuroscience 0270-6474/02/227650-12\$15.00/0 istration of an opioid such as morphine (Trujillo and Akil, 1991; Mao, 1999).

Activation of NMDARs can lead to neurotoxicity under many circumstances (Rothman and Olney, 1986; Swan and Meldrum, 1990; Moncada et al., 1992; Catania et al., 1993). For instance, peripheral nerve injury has been shown to activate spinal cord NMDARs, which results in not only intractable neuropathic pain but also neuronal cell death by means of apoptosis (Mao et al. 1992b, 1997; Kawamura et al., 1997; Whiteside and Munglani, 2001). Furthermore, cross talk between the cellular mechanisms of opioid tolerance and neuropathic pain has been proposed, suggesting that a common cellular mechanism may be involved in both neuropathic pain and opioid tolerance (Mao et al. 1995b; Mayer et al., 1999). Thus, it is possible that the cellular process leading to the development of opioid tolerance may also cause neurotoxic changes in response to prolonged opioid administration. Here we examined the hypothesis that neurotoxicity in the form of apoptotic cell death would be induced in association with the development of morphine tolerance.

At the synaptic level, glutamate, an endogenous ligand for the NMDAR, is actively and tightly regulated by the glutamate transporter (GT) system (Robinson and Dowd, 1997; Semba and Wakuta, 1998; Jabaudon et al., 2000). Indeed, the expression of GLT-1 (a glial GT) has been shown to be reduced after exposure to opioids in both cortical cell cultures (Thorlin et al., 1998) and brain regions (Ozawa et al., 2001), which may influence the development of morphine tolerance and dependence (Nakagawa et al., 2001). At the intracellular level, glutamate-induced neuro- 
nal apoptosis has been shown to be modulated by common intracellular regulators of apoptosis, including Bax, Bcl-2, and caspases (Du et al., 1997; Tenneti et al., 1998; Allen et al., 1999; Springer et al., 1999; Kwong and Lam, 2000; Nath et al., 2000; Puka-Sundvall et al., 2000; Qin et al., 2000; Tenneti and Lipton, 2000; Bachis et al., 2001; Chan et al., 2001). Thus, if prolonged exposure to an opioid induces apoptosis that is regulated through NMDAR-mediated glutamate neurotoxicity, one would expect to see the modulation of opioid-induced apoptosis by spinal GTs and NMDARs as well as by common intracellular regulators of apoptosis such as caspases. These possibilities were examined in the present study to investigate the cellular mechanisms of neuronal apoptosis associated with the development of morphine tolerance.

\section{MATERIALS AND METHODS}

\section{Experimental animals}

Adult male Sprague Dawley rats (Charles River Laboratories, Wilmington, MA) weighing 300-350 gm were used. Animals were housed in cages with water and food pellets available ad libitum. The animal room was artificially illuminated from 7 A.M. to 7 P.M. The experimental protocol was approved by our Institutional Animal Care and Use Committee.

\section{Intrathecal catheter and osmotic pump implantation}

An intrathecal PE 10 catheter was implanted in each rat according to a previously published method (Yaksh and Rudy, 1976). Those animals that exhibited neurological deficits after intrathecal catheter implantation were excluded from the experiments. Drugs were delivered via an intrathecal catheter in a total volume of $10 \mu \mathrm{l}$ followed by a saline flush. The following drugs were purchased from Sigma (St. Louis, MO): (+)-5-methyl-10,11-dihydro-5H-dibenzo [a,d] cyclohepten-5,10-imine maleate (MK-801), morphine, riluzole, L-trans-pyrrolidine-2-4dicarboxylate (PDC), N-benzyloxycarbonyl-Val-Ala-Asp-fluoromethyl ketone (Z-VAD-FMK), and acetyl-aspartyl-glutamyl-valyl-aspart-1aldehyde (AC-DEVD-CHO).

For continuous intrathecal infusion, osmotic minipumps (Alza, Mountain View, CA) were used as described previously (Granados-Soto et al., 2000; Vanderah et al., 2000). An osmotic pump, placed in a subcutaneous space after a surgical procedure, was connected to an intrathecal catheter via a piece of PE 60 catheter. The filled minipumps were soaked in normal saline for $4 \mathrm{hr}$ before the insertion to ensure immediate drug delivery. The integrity of the pump delivery system was reexamined at the end of each experiment when the spinal cords were harvested.

\section{Induction of morphine tolerance and behavioral test}

Tolerance to the antinociceptive effect of morphine was induced using two intrathecal treatment regimens: repeated boluses and continuous infusion. Morphine was given twice daily for $7 \mathrm{~d}$ in the repeated bolus regimen, whereas continuous morphine inf usion was made for $7 \mathrm{~d}$ via an implanted osmotic pump system delivering at $1 \mu \mathrm{l} / \mathrm{hr}$ for $7 \mathrm{~d}$. Differences in morphine antinociception among treatment groups were assessed on day 8 by the tail flick test at $30 \mathrm{~min}$ after a probe dose of either10 $\mu \mathrm{g}$ of morphine (intrathecal) for repeated bolus groups or $5 \mathrm{mg} / \mathrm{kg}$ morphine (intraperitoneal) for continuous infusion groups. Additionally, foot withdrawal latencies were compared among groups between day 0 (baseline) and the last day (day 8) of the experimental period to determine whether morphine-tolerant rats would develop increased sensitivity to noxious heat stimulation as shown in previous studies (Mao et al. 1995a; Ossipov et al., 1995; Vanderah et al., 2000). Because the osmotic pump infusion began on day 1, day 8 was the last day of a full 7 d delivery using an osmotic pump.

The routine tail flick test was made with baseline latencies of $4-5 \mathrm{sec}$ and a cutoff time of $10 \mathrm{sec}$ (D'Amour and Smith, 1941; Akil and Mayer, 1972). Three trials were made with an intertrial interval of 1 min and with changes of the tail position receiving radiant heat stimulation at each trial. The percent maximal possible antinociceptive effect (\%MPAE) was determined by comparing the tail flick latency before [baseline $(B L)$ ] and after a drug injection $(T L)$ using the equation $\% M P A E=[(T L-B L) /(10-B L)] \times 100$ (the constant 10 refers to the cutoff time). To examine changes in baseline nociceptive responses before and after a prolonged morphine administration, the foot withdrawal test with baseline latencies of 9-11 sec and a cutoff time of $20 \mathrm{sec}$ was used as described previously (Hargreaves et al., 1988). The foot withdrawal test was used because this test has been shown to be sensitive in detecting moderate changes in baseline nociceptive responses (Mao et al., 1994).

\section{In situ terminal deoxynucleotidyl transferase-mediated biotinylated UTP nick end-labeling staining}

The DNA fragmentation indicative of apoptosis can be demonstrated using several methods, including terminal deoxynucleotidyl transferasemediated biotinylated UTP nick end labeling (TUNEL), gel electrophoresis, and in situ nick translation (Gavrieli et al., 1992; Baba et al., 1999). In this study, we used the TUNEL method because this method allows us to examine the topographic distribution of apoptotic cells within the spinal cord dorsal horn, which cannot be shown using gel electrophoresis. Besides, it has been shown that apoptotic changes revealed by the TUNEL method are consistent with the gel electrophoresis data under several experimental conditions (Gavrieli et al., 1992; Lo et al., 1995). As described below, both positive and negative controls were included in the staining process and the costaining with Hoechst (for the in vivo detection of DNA), and TUNEL was used to ensure the consistency of the data collection. In addition, the morphology of TUNEL- and Hoechst-stained nuclei also was examined under a high-magnification microscopic view to identify features of apoptotic cells (e.g., condensed DNA segments and nuclear fragmentation).

A modified TUNEL staining protocol described in previous studies was followed (Gavrieli et al., 1992; Hara et al., 1995, 1998). Spinal cords from each group were collected after the final behavioral test on day 8 after transaortic perfusion with saline and a fixative containing $4 \%$ paraformaldehyde and cut into $10-\mu \mathrm{m}$-thick sections with a cryostat. One of every five such sections was mounted on a precoated slide. The TUNEL staining was performed using the apoptosis detection kit purchased from Roche Molecular Biochemicals (Indianapolis, IN). Briefly, the sections were first incubated in a solution containing $0.1 \%$ Triton $\mathrm{X}-100$ and $0.1 \%$ sodium citrate for $2 \mathrm{~min}$ on ice $\left(4^{\circ} \mathrm{C}\right)$ to increase the permeability. After being washed twice in $\mathrm{PBS}, \mathrm{pH} 7.4$, the sections were immersed in the TUNEL reaction mixture, containing biotinylated dUTP and terminal deoxynucleotidyl transferase (TdT) conjugated with fluorochromes (tetramethylrhodamine red) for $60 \mathrm{~min}$ at $37^{\circ} \mathrm{C}$ in a dark, humidified atmosphere. The process was terminated by washing the sections twice in a blocking buffer (PBS, Triton X-100, and BSA). In each assay, negative controls were included using the same incubation procedure but omitting TdT in the process, whereas positive controls were performed by incubating the permeated sections with DNase $(1 \mu \mathrm{g} / \mathrm{ml})$ to induce DNA strand breakage.

\section{Immunocytochemical and Hoechst staining}

Routine immunocytochemical staining (Ji et al., 1995) was used to detect neuronal-specific nuclear protein (NeuN) (1:500, a marker for neuronal nuclear protein; Mullen et al., 1992), glutamic acid decarboxylase 67 (GAD67; 1:1000), Bax (1:250), caspase-3 (1:500), and cleaved caspase-3 (1:50). All antibodies were purchased from Chemicon (Temecula, CA) except for the cleaved caspase-3 antibody (Cell Signaling Technology, Beverly, MA). The process of harvesting, fixing, and slicing spinal cord samples was the same as that used for the TUNEL procedure. After the TUNEL staining, sections were blocked with $1 \%$ goat serum in $0.3 \%$ Triton X-100 for $1 \mathrm{hr}$ at room temperature and incubated overnight at $4^{\circ} \mathrm{C}$ with a primary antibody. The sections were then incubated for $1 \mathrm{hr}$ at room temperature with a corresponding FITC-conjugated secondary antibody (1:300; Chemicon). The Hoechst staining (Hoechst 33342) was used for the in vivo detection of DNA in spinal sections. Colocalization of TUNEL with NeuN, GAD67, caspase-3, Bax, or Hoechst staining was examined by an imaging program (Adobe Photoshop).

\section{Cell counting}

Five or six sections randomly selected from each animal were analyzed by using a fluorescence microscope linked to a digital camera. Numbers of apoptotic cells were counted in a blinded manner for both sides of each spinal section, in which three regions (laminas I-II, III-IV, and V-VI) were divided based on the laminar delineation described previously (Molander et al., 1984; Mao et al. 1992a, 1993). These regions were chosen because they represent functional subdivisions of the spinal cord dorsal horn (Price, 1988). Two approaches were used to display these 
laminar divisions. Spinal sections were either counterstained with Nissl staining or costained with NeuN staining. Both methods have been commonly used to outline spinal cord dorsal horn divisions based on distinct laminar patterns described by Molander et al. (1984). Because the TUNEL staining is only visible in the cell body, and sections selected for the analysis were chosen from at least $50 \mu \mathrm{m}$ apart (see above), this analysis avoided double counting the number of apoptotic cells. To analyze sections with costainings (e.g., TUNEL and caspase-3), images from each staining were digitized and then merged using an imaging program (Adobe) to examine the presence of colocalization.

\section{Western analysis of Bax, Bcl-2, and caspase-3}

For Western blotting, rats were rapidly $(<1 \mathrm{~min})$ killed in a $\mathrm{CO}_{2}$ chamber, and the dorsal horns of the lumbar spinal cord segments were removed and homogenized in SDS sample buffer containing a mixture of proteinase inhibitors (Sigma). The lumbar segments were harvested because an intrathecal catheter was aimed to deliver drugs at this site. Protein samples were separated on an SDS-PAGE gel (4-15\% gradient gel; Bio-Rad, Hercules, CA) and transferred to polyvinylidene difluoride filters (Millipore, Bedford, MA). The filters were blocked with $3 \%$ milk and incubated overnight at $4^{\circ} \mathrm{C}$ with a primary antibody (Bax, 1:100; caspase-3, 1:1000 for 19 and $32 \mathrm{kDa}$; and $\mathrm{Bcl}-2,1: 5000)$ and $1 \mathrm{hr}$ at room temperature with an HRP-conjugated secondary antibody (1:5000; Amersham Biosciences, Arlington Heights, IL). The blots were then visualized in ECL solution (PerkinElmer Life Sciences, Emeryville, CA) for 1 $\mathrm{min}$ and exposed onto hyperfilms (Amersham) for 1-10 min. The gray density of each blot was obtained for each experimental group. The same amounts of protein for each loading lane were estimated by the Bio-Rad protein assay, and the extracellular signal-regulated kinase (ERK) protein was used as a loading control.

\section{Experimental design}

Experiment 1: induction of apoptosis after morphine tolerance. Seven groups of rats were used in this experiment. To investigate whether repeated exposure to morphine boluses would result in the induction of apoptosis, three groups of rats $(n=5)$ were each given 10 or $20 \mu \mathrm{g}$ of intrathecal morphine or saline twice daily for $7 \mathrm{~d}$. In addition, three more groups of rats $(n=5)$ were infused, via an intrathecal osmotic pump for $7 \mathrm{~d}$, with 10 or $20 \mathrm{nmol} \cdot \mu \mathrm{l}^{-1} \cdot \mathrm{hr}^{-1}$ morphine or saline to determine whether apoptosis would be induced using continuous infusion. This treatment regimen was included because repeated morphine boluses have been suggested to cause intermittent opioid withdrawals, a process that could increase NMDAR activity via glutamate release independent of the intracellular mechanisms of opioid tolerance (Ibuki et al., 1997; Dunbar and Pulai, 1998). In either treatment regimen, morphine doses were chosen on the basis of the previous studies that showed the development of morphine tolerance using these doses (Mao et al., 1994; Ibuki et al., 1997). An additional group of rats $(n=4)$ was included to examine whether apoptosis occurred in response to an acute morphine effect after a single intrathecal injection of $20 \mu \mathrm{g}$ of morphine. In all groups, spinal cords were harvested after the final behavioral test as described above.

To investigate the neurochemical nature of apoptotic cells, the spinal sections were examined for the colocalization of TUNEL and GAD, a key enzyme for the synthesis of the inhibitory neurotransmitter GABA. Furthermore, neuronal apoptosis was identified by examining the colocalization of TUNEL and NeuN as described above.

Experiment 2: role of the spinal GT and NMDAR in morphine-induced apoptosis. To investigate whether perturbation of spinal GT activity would affect opioid-induced apoptosis, PDC, a GT inhibitor (Lievens et al., 2000; Matthews et al., 2000), and riluzole, a positive GT regulator (Azbill et al., 2000), were used in this set of experiments. Although riluzole was initially considered as an inhibitor of the presynaptic glutamate release (Cheramy et al., 1992; Doble, 1996), this agent has been shown recently to be a positive GT regulator that increases glutamate uptake in synaptosomes under both in vivo and in intro conditions (Azbill et al., 2000). Four groups of rats $(n=5)$ were used, including (1) $10 \mu \mathrm{g}$ of morphine plus $20 \mu \mathrm{g}$ of riluzole, (2) $20 \mu \mathrm{g}$ of riluzole alone, (3) $10 \mu \mathrm{g}$ of morphine plus $20 \mu \mathrm{g}$ of PDC, and (4) $20 \mu \mathrm{g}$ of PDC alone. The drugs or their combinations were given intrathecal twice daily for $7 \mathrm{~d}$ and these groups were compared with those receiving $10 \mu \mathrm{g}$ of morphine or saline alone in experiment 1 . The dose for riluzole or PDC was selected on the basis of a pilot study showing a reliable effect of each agent at this dose on modulating the development of morphine (10 $\mu \mathrm{g}$, intrathecal) tolerance. In addition, the equivalent doses of PDC and riluzole have been shown to be effective in regulating the extracellular glutamate concen- tration and NMDAR-mediated activity under both in vivo and in vitro experimental conditions (Semba and Wakuta, 1998; Azbill et al., 2000; Jabaudon et al., 2000; Lievens et al., 2000; Matthews et al., 2000).

To determine the role of NMDARs in the induction of neuronal apoptosis, two more groups of rats each received a $7 \mathrm{~d}$ intrathecal infusion with either $20 \mathrm{nmol} \cdot \mu \mathrm{l}^{-1} \cdot \mathrm{hr}^{-1}$ morphine plus 1 $\mathrm{nmol} \cdot \mu \mathrm{l}^{-1} \cdot \mathrm{hr}^{-1} \mathrm{MK}-801(n=9)$ or $1 \mathrm{nmol} \cdot \mu \mathrm{l}^{-1} \cdot \mathrm{hr}^{-1} \mathrm{MK}-801$ alone $(n=6)$. The dose for MK-801 was selected on the basis of a previous study showing the blockade of morphine tolerance by this dose of MK-801 (Ibuki et al., 1997). The data from these groups were compared with those from the $20 \mathrm{nmol} \cdot \mu \mathrm{l}^{-1} \cdot \mathrm{hr}^{-1}$ morphine- or saline-alone groups in experiment 1 .

Experiment 3: role of intracellular apoptosis regulators in morphineinduced apoptosis. To examine the intracellular mechanisms of morphine-induced apoptosis, two approaches were used. First, changes in Bax, caspase-3, and Bcl-2 were examined using the methods of Western blotting and immunocytochemistry in rats receiving either $20 \mu \mathrm{g}$ of morphine or saline ( $n=8-10$ per group for separate sample collections) twice daily for $7 \mathrm{~d}$. Second, additional groups of rats ( $n=4-6$ per group) were used to examine whether blockade of caspases including caspase-3 would prevent morphine-induced apoptosis. Thus, each group of rats received intrathecal (1) saline, (2) $20 \mu \mathrm{g}$ of morphine plus vehicle, (3) 20 $\mu \mathrm{g}$ of morphine plus $5 \mu \mathrm{g}$ of Z-VAD-FMK (a pan-caspase inhibitor), or (4) $20 \mu \mathrm{g}$ of morphine plus $5 \mu \mathrm{g}$ of AC-DEVD-CHO (a relatively selective caspase-3 inhibitor) twice daily for $7 \mathrm{~d}$. The selected dose for each agent was based on previous studies showing a reliable inhibition of the caspase-like activity in vivo within this intrathecal dose range (Qin et al., 2000; Chan et al., 2001). For additional controls, rats $(n=3-4$ per group) received a $7 \mathrm{~d}$ intrathecal treatment (twice daily) with the same dose of Z-VAD-FMK or AC-DEVD-CHO alone. A single dose of $10 \mu \mathrm{g}$ of morphine was given on day 8 to examine whether Z-VAD-FMK or AC-DEVD-CHO alone would affect morphine-induced antinociception.

\section{Statistical analysis}

Data obtained from the tail flick test were first calculated to yield the mean \%MPAE as shown previously (Mao et al., 1994). The data were then analyzed by using two-way ANOVA to detect overall differences among treatment groups. When significant main effects were observed, Waller-Duncan (WD) K ratio $t$ tests (WD) were performed to determine sources of differences. The histological data (cell counting) from each spinal section were first averaged for each dorsal horn region and then analyzed using ANOVA followed by the WD test to determine the statistical differences. Paired Student's $t$ test was used to examine statistical differences in the gray density of Western blots.

\section{RESULTS}

\section{Induction of neuronal apoptosis associated with morphine tolerance}

Twice daily administration of 10 or $20 \mu \mathrm{g}$ of morphine for $7 \mathrm{~d}$ produced, dose-dependently, tolerance to the antinociceptive effect of morphine when tested on day 8 (Fig. $1 A)(p<0.01)$. This morphine treatment regimen induced apoptotic cells within the spinal cord dorsal horn of the same rats (Fig. 2B). The in situ detection of DNA fragmentation by the TUNEL method was further indicated by the colocalization of both TUNEL and Hoechst (detecting in situ DNA) staining in the same cells (Fig. $2 D-F)$. Moreover, features of apoptotic cells were observed in the TUNEL and Hoechst costained nuclei including nuclear fragmentation and condensed DNA segments (Fig. $2 D^{\prime}-F^{\prime}$ ). In contrast, apoptotic cells were hardly detectable in saline-treated rats (Figs. $2 A, 3 A)(p<0.01)$, indicating that the induction of apoptosis is specifically associated with morphine treatment. Likewise, few apoptotic cells were present in rats receiving a single intrathecal treatment of $20 \mu \mathrm{g}$ of morphine (Fig. $3 A)(p>$ $0.05)$, indicating that the induction of apoptosis is not attributable to an acute morphine effect.

Similar to the results obtained using the bolus treatment regimen, tolerance to the morphine antinociception developed dosedependently when tested on day 8 in rats receiving 10 or 20 

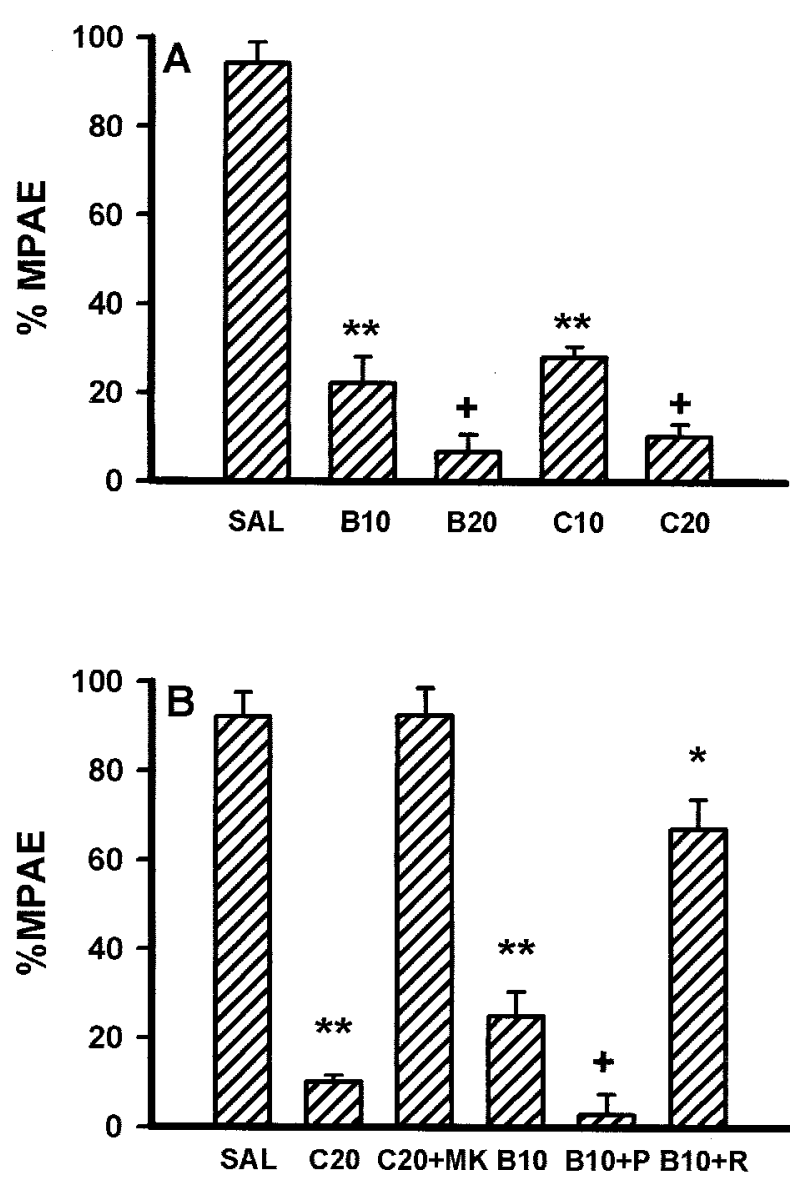

Figure 1. Modulation of morphine tolerance by regulating spinal GT and NMDAR activity. $A$, When tested on day $8, \%$ MPAE in response to 20 $\mu \mathrm{g}$ of intrathecal morphine was reduced in rats treated with 10 or $20 \mu \mathrm{g}$ of intrathecal morphine $(B 10, B 20)$ twice daily for $7 \mathrm{~d}$. Similarly, \%MPAE in response to $5 \mathrm{mg} / \mathrm{kg}$ morphine (intraperitoneally) on day 8 was reduced in rats receiving a $7 \mathrm{~d}$ infusion, via an intrathecal osmotic pump, with 10 or $20 \mathrm{nmol} \cdot \mu \mathrm{l}^{-1} \cdot \mathrm{hr}^{-1}$ morphine $(C 10, C 20)$. In both treatment regimens, the development of morphine tolerance was dose-dependent. $B$, MK-801 $\left(1 \mathrm{nmol} \cdot \mu \mathrm{l}^{-1} \cdot \mathrm{hr}^{-1}\right)$ blocked the development of tolerance when given with morphine $\left(20 \mathrm{nmol} \cdot \mu \mathrm{l}^{-1} \cdot \mathrm{hr}^{-1}\right)$ for $7 \mathrm{~d}(C 20+M K)$. Twice daily coadministration of $10 \mu \mathrm{g}$ of morphine and $20 \mu \mathrm{g}$ of PDC (a GT inhibitor; $B 10+P$ ) for $7 \mathrm{~d}$ potentiated, whereas combined $10 \mu \mathrm{g}$ of morphine and $20 \mu \mathrm{g}$ of riluzole (a positive GT regulator; $B 10+R$ ) reduced, the development of morphine tolerance when tested on day 8 with a probe dose of $20 \mu \mathrm{g}$ of morphine (intrathecal). ${ }^{*} p<0.05 ;{ }^{*} p<0.01$ compared with the corresponding saline group; ${ }^{+} p<0.05$ compared with the corresponding low-dose morphine group $(A)$ or the morphine-alone group $(B)$.

nmol $\cdot \mu \mathrm{l}^{-1} \cdot \mathrm{hr}^{-1}$ morphine, but not saline, inf usion for $7 \mathrm{~d}$ (Fig. 1A) $(p<0.01)$. Consistently, apoptotic cells were observed in morphine- but not saline-infused rats (Fig. $3 A)(p<0.01)$. Both the distribution and quantity of apoptotic cells were comparable with those seen in rats treated with morphine boluses (Fig. $3 A$ ). In both experiments, more apoptotic cells were observed in rats receiving a high dose $\left(20 \mu \mathrm{g}\right.$ or $\left.20 \mathrm{nmol} \cdot \mu \mathrm{l}^{-1} \cdot \mathrm{hr}^{-1}\right)$ than a low dose $\left(10 \mu \mathrm{g}\right.$ or $\left.10 \mathrm{nmol} \cdot \mu \mathrm{l}^{-1} \cdot \mathrm{hr}^{-1}\right)$ of morphine (Fig. $\left.3 A\right)(p<$ $0.05)$, indicating that the induction of apoptosis was dose-dependent.

Topographically, these apoptotic cells were primarily located in laminas I-II of the spinal cord dorsal horn of rats receiving either repeated or continuous morphine administration (Table 1). Furthermore, most apoptotic cells were identified as neuronal cells
(Fig. 3B), because both apoptosis (TUNEL) and neuronal $(\mathrm{NeuN})$ markers were colocalized in the same cells (Fig. 2G-I). Because the total number of apoptotic cells exceeded that of neuronal apoptotic cells (Fig. $3 B$ ), it is likely that some of these apoptotic cells were glial cells (Fig. $2 G-I$ ). Thus, apoptosis was induced in the spinal cord dorsal horn of rats made tolerant to morphine after either repeated bolus or continuous intrathecal administration.

\section{Expression of the GABA-synthesizing enzyme GAD in apoptotic neuronal cells}

Spinal sections from rats receiving either repeated $20 \mu \mathrm{g}$ morphine boluses or $20 \mathrm{nmol} \cdot \mu \mathrm{l}^{-1} \cdot \mathrm{hr}^{-1}$ morphine infusion for $7 \mathrm{~d}$ were costained with TUNEL and GAD67. Colocalization of both TUNEL and GAD67 immunostaining was clearly observed within the superficial spinal cord dorsal horn laminas (Fig. 2J-L). As shown in Figure $3 B,>50 \%$ of apoptotic cells from each group displayed positive GAD67 immunostaining. Given the observation that a portion of apoptotic cells are likely to be glial cells (Fig. 2G-I) and that GAD is expected to be visualized only in neuronal cells, the data indicate that many apoptotic neuronal cells are likely to be GABAergic inhibitory neurons.

\section{Increased nociceptive heat sensitivity in rats showing neuronal apoptosis}

The baseline foot withdrawal latency was compared between day 0 (baseline) and day 8 in each group. There was no significant difference in the foot-withdrawal latency between days 0 and 8 in the saline-treated rats (Fig. $4 A)(p>0.05)$. In contrast, the baseline foot withdrawal latency was reduced on day 8 , compared with that on day 0 (Fig. $4 A)(p<0.01)$ in rats receiving either repeated boluses or continuous infusion with morphine for $7 \mathrm{~d}$. Similar to that observed with morphine tolerance (Fig. 1) and associated neuronal apoptosis (Fig. $3 A$ ), the magnitude of increase in nociceptive sensitivity was also dose-dependent. That is, a significantly lower baseline foot withdrawal latency was observed in rats treated with a high dose $\left(20 \mu \mathrm{g}\right.$ or $\left.20 \mathrm{nmol} \cdot \mu \mathrm{l}^{-1} \cdot \mathrm{hr}^{-1}\right)$ than a low dose $\left(10 \mu \mathrm{g}\right.$ or $\left.10 \mathrm{nmol} \cdot \mu \mathrm{l}^{-1} \cdot \mathrm{hr}^{-1}\right)$ of morphine (Fig. $4 A)(p<0.05)$. These results indicate that the induction of neuronal apoptosis in morphine-tolerant rats was accompanied by an increase in the sensitivity to noxious heat stimulation, a finding consistent with that demonstrated by previous studies (Mao et al. 1995a; Ossipov et al., 1995; Vanderah et al., 2000).

\section{Contribution of the spinal GT and NMDAR to the induction of neuronal apoptosis}

Intrathecal coadministration (twice daily) of morphine $(10 \mu \mathrm{g})$ and the GT inhibitor PDC (20 $\mu \mathrm{g})$ for $7 \mathrm{~d}$ further increased the number of apoptotic cells within the superficial spinal cord dorsal horn compared with that of the morphine-alone $(10 \mu \mathrm{g})$ group (Figs. $2 A-C, 5 A)(p<0.01)$. Conversely, apoptotic cells were reduced in rats receiving combined morphine $(10 \mu \mathrm{g})$ and riluzole (20 $\mu \mathrm{g}$, a positive regulator of GT activity) for $7 \mathrm{~d}$ compared with that of the morphine-alone group (Fig. 5A) $(p<0.05)$. Neither PDC nor riluzole alone at the current dose induced apoptotic changes (Fig. 5A). Furthermore, riluzole and PDC at its current dose also reduced and enhanced, respectively, the development of morphine tolerance and changes in nociceptive sensitivity in the behavioral tests (Figs. $1 B, 4 B$ ). Thus, regulation of the spinal GT activity contributes to the induction of apoptosis associated with the development of morphine tolerance and the increase in nociceptive heat sensitivity.

Consistent with the role of spinal GT activity, apoptosis was 

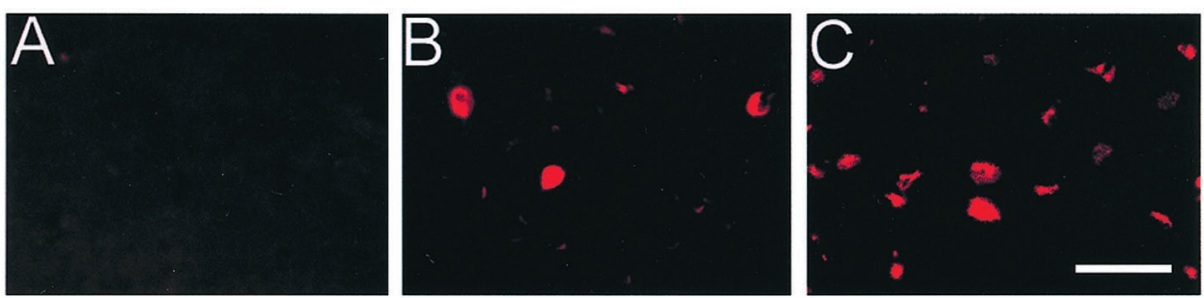

Figure 2. Induction of neuronal apoptosis after prolonged morphine treatment. $A-C$, Micrographs from the superficial spinal cord dorsal horn illustrate apoptotic cells in rats receiving repeated intrathecal saline $(A), 10$ $\mu \mathrm{g}$ morphine boluses $(B)$, and the combination of $10 \mu \mathrm{g}$ of morphine and $20 \mu \mathrm{g}$ of PDC (C) for $7 \mathrm{~d}$. $D-F$, The TUNEL (red) staining colocalizes with condensed and fragmented nuclei, as shown by the Hoechst staining (blue) and the merged image in $F$, indicating that the TUNEL staining specifically detected in vivo DNA fragmentation (arrows). Note that all TUNEL-positive cells were colocalized with the Hoechst staining. $D^{\prime}-F^{\prime}$, Note the highmagnification views of these insets (arrows) from $D-F$ showing nuclear fragmentation and condensed DNA segments. $G-I$, The TUNEL (red) staining was colocalized with the NeuN staining (green) as shown in I (merged), indicating that the costained apoptotic cells were neurons in the dorsal horn. Note that some TUNEL-positive cells were not colocalized with NeuN, indicating the presence of apoptotic glial cells. $J-L$, The TUNEL (red) staining was colocalized with the GAD67 staining (green) as shown in $L$ (merged), indicating that the costained apoptotic cells contain the GABA-synthesizing enzyme and are likely to be GABAergic neurons. Images from $D-L$ were taken from rats receiving intrathecal 20 $\mu \mathrm{g}$ morphine boluses or $20 \mathrm{nmol} \cdot \mu \mathrm{l}^{-1} \cdot \mathrm{hr}^{-1}$ morphine infusion for $7 \mathrm{~d}$. Scale bars: $A-C, 30$ $\mu \mathrm{m} ; D-L, 15 \mu \mathrm{m} ; D^{\prime}-F^{\prime}, 5 \mu \mathrm{m}$.
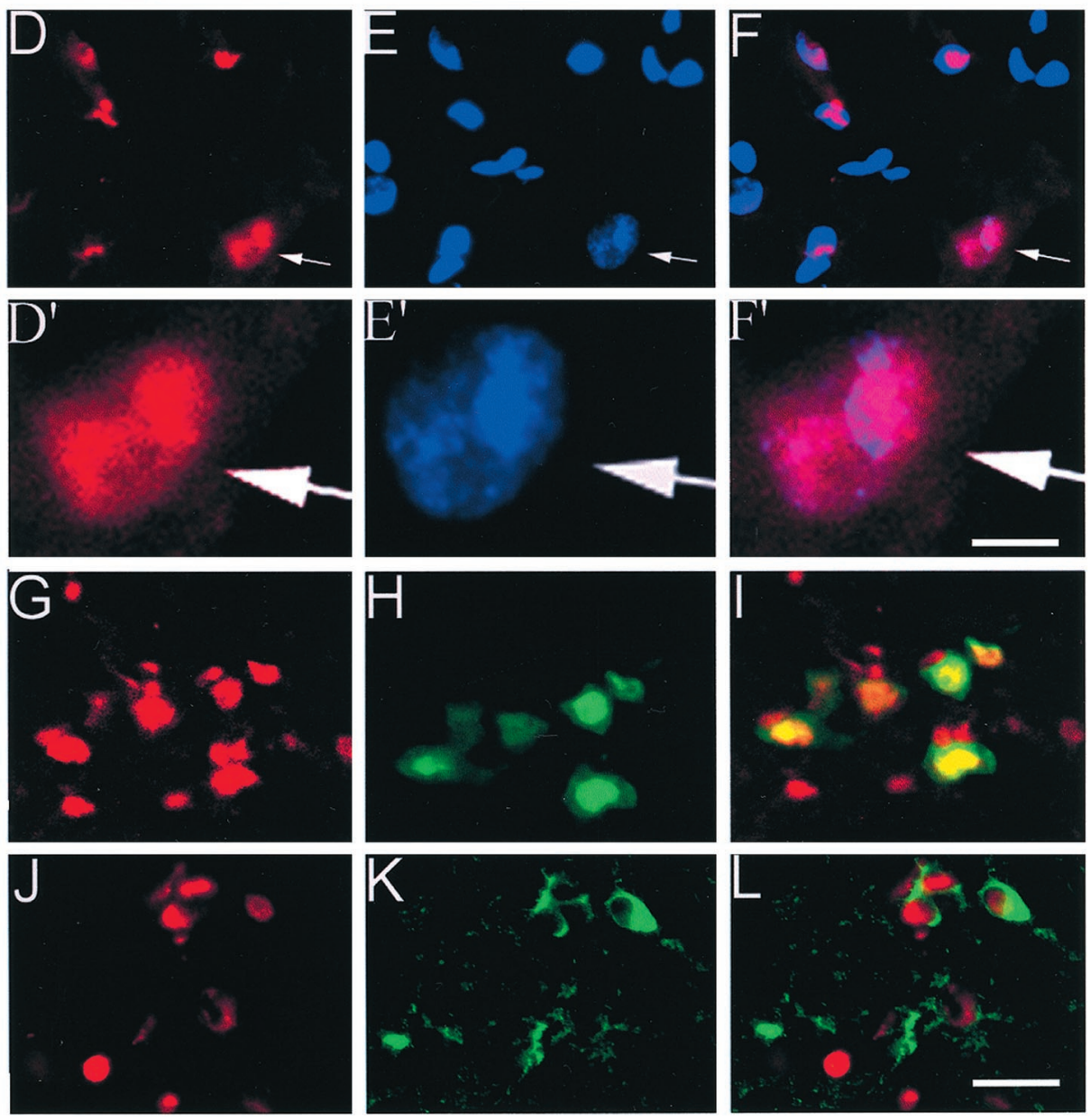

clearly blocked in rats receiving coadministration of morphine $\left(20 \mathrm{nmol} \cdot \mu \mathrm{l}^{-1} \cdot \mathrm{hr}^{-1}\right)$ and MK-801 $\left(1 \mathrm{nmol} \cdot \mu \mathrm{l}^{-1} \cdot \mathrm{hr}^{-1}\right.$, a noncompetitive NMDAR antagonist) via an intrathecal osmotic pump for $7 \mathrm{~d}$ compared with the corresponding morphine-alone group (Fig. $5 B)(p<0.01)$. The combined administration with morphine and MK-801 also effectively prevented the development of morphine tolerance (Fig. $1 B$ ) as well as the increase in nociceptive heat sensitivity (Fig. $4 B$ ) when tested on day 8 . Neither apoptosis nor changes in morphine antinociception were observed on day 8 in rats infused with MK-801 (1 $\mathrm{nmol} \cdot \mu \mathrm{l}^{-1} \cdot \mathrm{hr}^{-1}$, intrathecal) alone for $7 \mathrm{~d}$, indicating that MK801 specifically blocked the process of morphine tolerance and neuronal apoptosis.

\section{Changes in the spinal caspase-3, Bax, and Bcl-2 protein content in morphine-tolerant rats}

Intrathecal administration (twice daily) of $20 \mu \mathrm{g}$ of morphine for $7 \mathrm{~d}$ induced an upregulation of Bax and caspase- 3 but a downregulation of $\mathrm{Bcl}-2$ in the spinal cord dorsal horn, as shown in corresponding Western blots (Fig. 6). Consistently, there was an increase in cell bodies positively stained with cleaved caspase- 3 in the superficial dorsal horn of rats treated with 20 $\mathrm{nmol} \cdot \mu \mathrm{l}^{-1} \cdot \mathrm{hr}^{-1}$ morphine but not saline for $7 \mathrm{~d}$ (Figs. $7 A, B$, $8 A)$. Such an increase in caspase-3-positive cells was blocked by the coadministration of morphine $\left(20 \mathrm{nmol} \cdot \mu \mathrm{l}^{-1} \cdot \mathrm{hr}^{-1}\right)$ with MK-801 $\left(1 \mathrm{nmol} \cdot \mu \mathrm{l}^{-1} \cdot \mathrm{hr}^{-1}\right)$ for $7 \mathrm{~d}$ (Fig. $\left.8 A\right)$, suggesting that NMDARs play an important role in the caspase-3 increase in morphine-tolerant rats. Importantly, caspase-3 or Bax was colocalized with the TUNEL staining in the spinal cord dorsal horn (Fig. $7 \mathrm{C}-\mathrm{H}$ ), indicating a morphological correlation at the cellular level between caspase-3 or Bax changes and neuronal apoptosis.

\section{Contribution of the spinal caspase-like activity to the induction of neuronal apoptosis}

Consistent with the immunocytochemical and Western blot findings, coadministration of $20 \mu \mathrm{g}$ of morphine with the pan-caspase inhibitor Z-VAD-FMK $(5 \mu \mathrm{g})$ or the relatively selective caspase-3 inhibitor AC-DEVD-CHO $(5 \mu \mathrm{g})$ for $7 \mathrm{~d}$ prevented the induction of neuronal apoptosis compared with that of the 

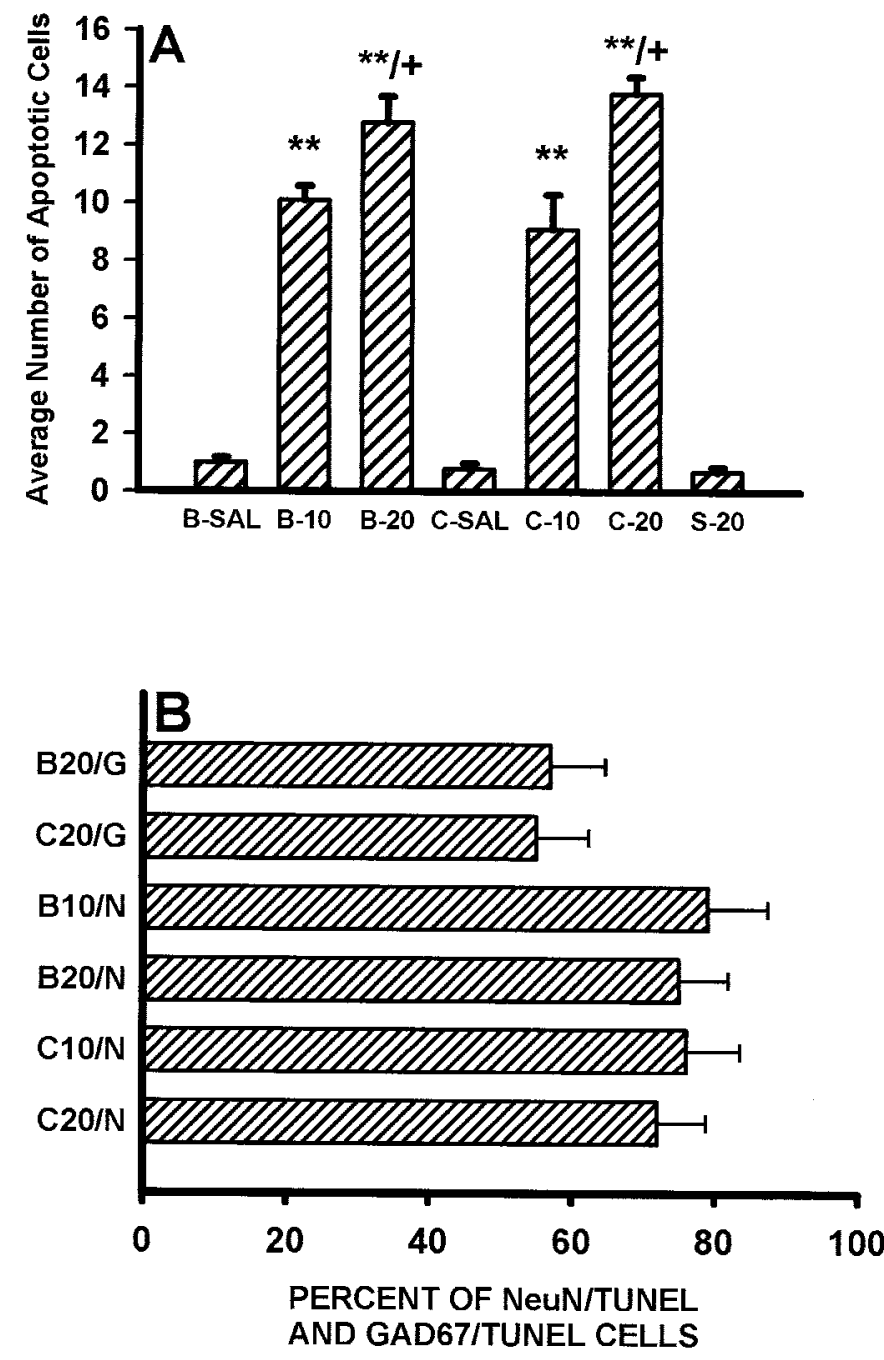

Figure 3. Quantification of apoptotic cells and percentage of NeuN- and TUNEL- or GAD67- and TUNEL-positive cells. $A$, Dose-dependent change in apoptotic cells within the spinal cord dorsal horn of rats treated with either repeated morphine boluses or continuous infusion for $7 \mathrm{~d}$. Neither saline nor a single intrathecal morphine $(20 \mu \mathrm{g})$ injection induced significant apoptotic cells. $B$, A large percentage of apoptotic cells were identified as NeuN- and TUNEL-positive apoptotic neurons. A considerable number of apoptotic cells also expressed GAD (GAD67/TUNEL $C E L L S)$, suggesting that these cells may be GABAergic neurons. Note that the percentage of GAD67- and TUNEL-positive cells is smaller than that of NeuN- and TUNEL-positive cells, indicating that not all apoptotic neurons are GAD-positive cells. The percent of costained cells was calculated as the number of costained cells divided by the total TUNELstained cells in each category $\times 100 \%$. $B-S A L$, Saline boluses; $B-10, B-20$, intrathecal 10 and $20 \mu \mathrm{g}$ morphine boluses; $C$-SAL, continuous saline infusion; $C$-10, $C$-20, intrathecal 10 and $20 \mathrm{nmol} \cdot \mu \mathrm{l}^{-1} \cdot \mathrm{hr}^{-1}$ continuous morphine infusion; $S$-20, a single intrathecal injection of $20 \mu \mathrm{g}$ of morphine; $B 20 / G, C 20 / G$, GAD67 and TUNEL costaining in sections taken from rats receiving $20 \mu \mathrm{g}$ morphine boluses or $20 \mathrm{nmol} \cdot \mu \mathrm{l}^{-1} \cdot \mathrm{hr}^{-1}$ continuous morphine infusion; B10/N,B20/N,C10/N,C20/N, NeuN and TUNEL costaining in sections taken from rats receiving 10 or $20 \mu \mathrm{g}$ morphine boluses and $10 \mathrm{or} 20 \mathrm{nmol} \cdot \mu \mathrm{l}^{-1} \cdot \mathrm{hr}^{-1}$ continuous morphine infusion. ${ }^{* *} p<0.01$, compared with the corresponding saline groups; ${ }^{+} p<0.05$, compared with the corresponding low-dose morphine group.

morphine-alone $(20 \mu \mathrm{g})$ group (Fig. $8 B)(p<0.01)$. Neither Z-VAD-FMK nor AC-DEVD-CHO alone induced apoptotic changes. Furthermore, both tolerance to the antinociceptive effects of morphine and the increase in nociceptive sensitivity were partially prevented in rats receiving the coadministration of mor-

Table 1. Laminal distribution of apoptotic cells
\begin{tabular}{lcll} 
Group & I-II & III-IV & V-V I \\
\hline Saline bolus & $0.5 \pm 0.3$ & $0.2 \pm 0.2$ & $0.3 \pm 0.3$ \\
$10 \mu \mathrm{g}$ MS bolus & $8.7 \pm 0.6^{*}$ & $0.3 \pm 0.1$ & $1.1 \pm 0.3^{* *}$ \\
$20 \mu \mathrm{g} \mathrm{MS} \mathrm{bolus}$ & $10.7 \pm 1.3^{* * *}$ & $0.5 \pm 0.1$ & $1.6 \pm 0.4^{* *}$ \\
Saline infusion & $0.4 \pm 0.2$ & $0.2 \pm 0.2$ & $0.2 \pm 0.4$ \\
$10 \mathrm{nmol} \cdot \mu \mathrm{l}^{-1} \cdot \mathrm{hr}^{-1} \mathrm{MS}$ & $8.1 \pm 1.5^{*}$ & $0.4 \pm 0.3$ & $0.6 \pm 0.3$ \\
$20 \mathrm{nmol} \cdot \mu \mathrm{l}^{-1} \cdot \mathrm{hr}^{-1} \mathrm{MS}$ & $11.9 \pm 0.7^{* * *}$ & $0.6 \pm 0.1$ & $0.9 \pm 0.4^{* *}$
\end{tabular}

The data represent the mean \pm SE number of apoptotic cells in a given group averaged from five or six sections per rat. ${ }^{*} p<0.01 ;{ }^{* *} p<0.05$, compared with the saline group, ${ }^{* * *} p<0.01$ compared with both saline and $10 \mu \mathrm{g}$ or $10 \mathrm{nmol} \cdot \mu \mathrm{l}^{-1} \cdot \mathrm{hr}^{-1}$ morphine (MS) groups.
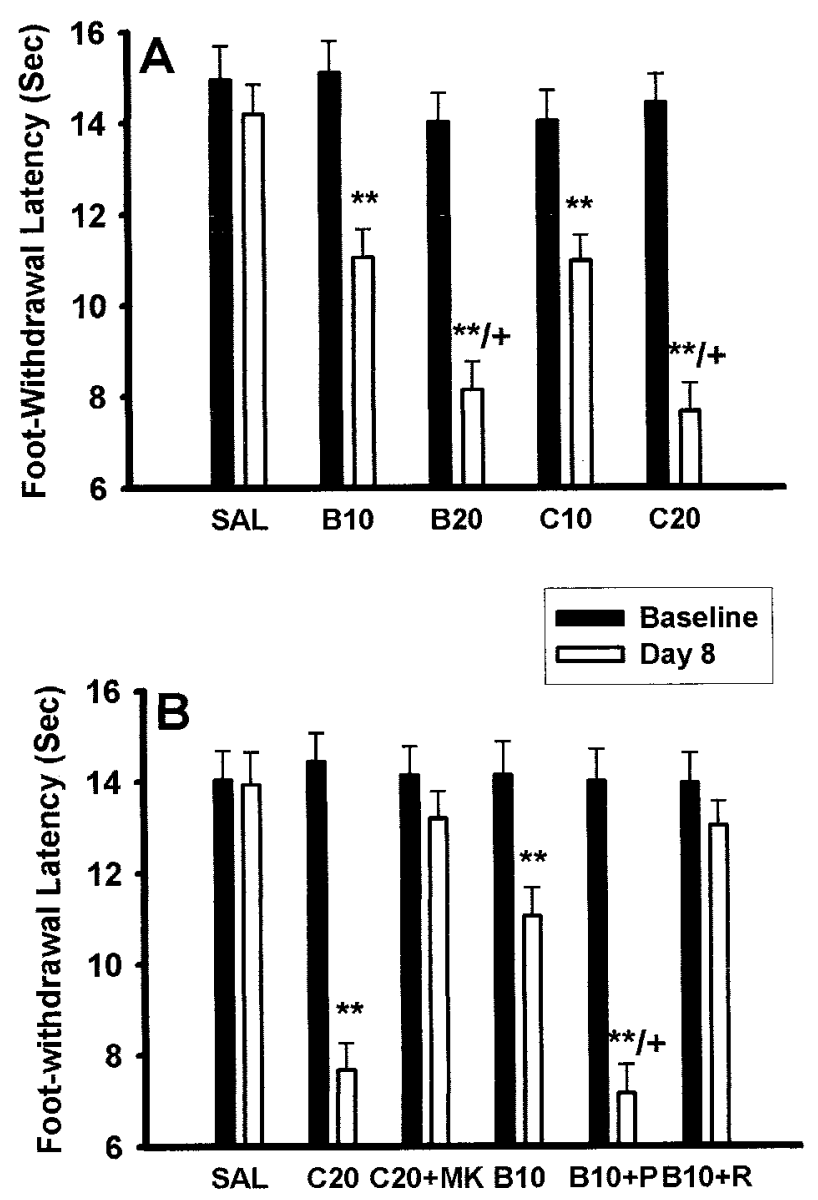

Figure 4. Modulation of increased nociceptive sensitivity by regulating the spinal GT and NMDAR activity. $A$, The baseline foot withdrawal latency was dose-dependently reduced on day 8 compared with that on day 0 in rats receiving either repeated boluses $(B 10, B 20)$ or continuous infusion with morphine $(C 10, C 20)$ for $7 \mathrm{~d}$, indicating an increased nociceptive heat sensitivity. $B, \mathrm{MK}-801\left(1 \mathrm{nmol} \cdot \mu \mathrm{l}^{-1} \cdot \mathrm{hr}^{-1}\right)$ blocked the increased nociceptive heat sensitivity when coadministered with morphine (20 $\left.\mathrm{nmol} \cdot \mu \mathrm{l}^{-1} \cdot \mathrm{hr}^{-1}\right)$ for $7 \mathrm{~d}(C 20+M K)$. Similarly, coadministration (twice daily for $7 \mathrm{~d})$ of $10 \mu \mathrm{g}$ of morphine and $20 \mu \mathrm{g}$ of PDC $(B 10+P)$ potentiated, whereas combined $10 \mu \mathrm{g}$ of morphine and $20 \mu \mathrm{g}$ of riluzole $(B 10+R)$ reduced, the increase in nociceptive heat sensitivity. ${ }^{* *} p<0.01$, compared with baseline foot withdrawal latencies on day 0 in the same group; ${ }^{+} p<$ 0.05 , compared with the corresponding morphine-alone group.

phine and Z-VAD-FMK or AC-DEVD-CHO (Fig. $8 C, D$ ), whereas Z-VAD-FMK or AC-DEVD-CHO (5 $\mu \mathrm{g}$, intrathecal) alone for $7 \mathrm{~d}$ did not change baseline latencies and the response to the antinociceptive effects of morphine. These results indicate 

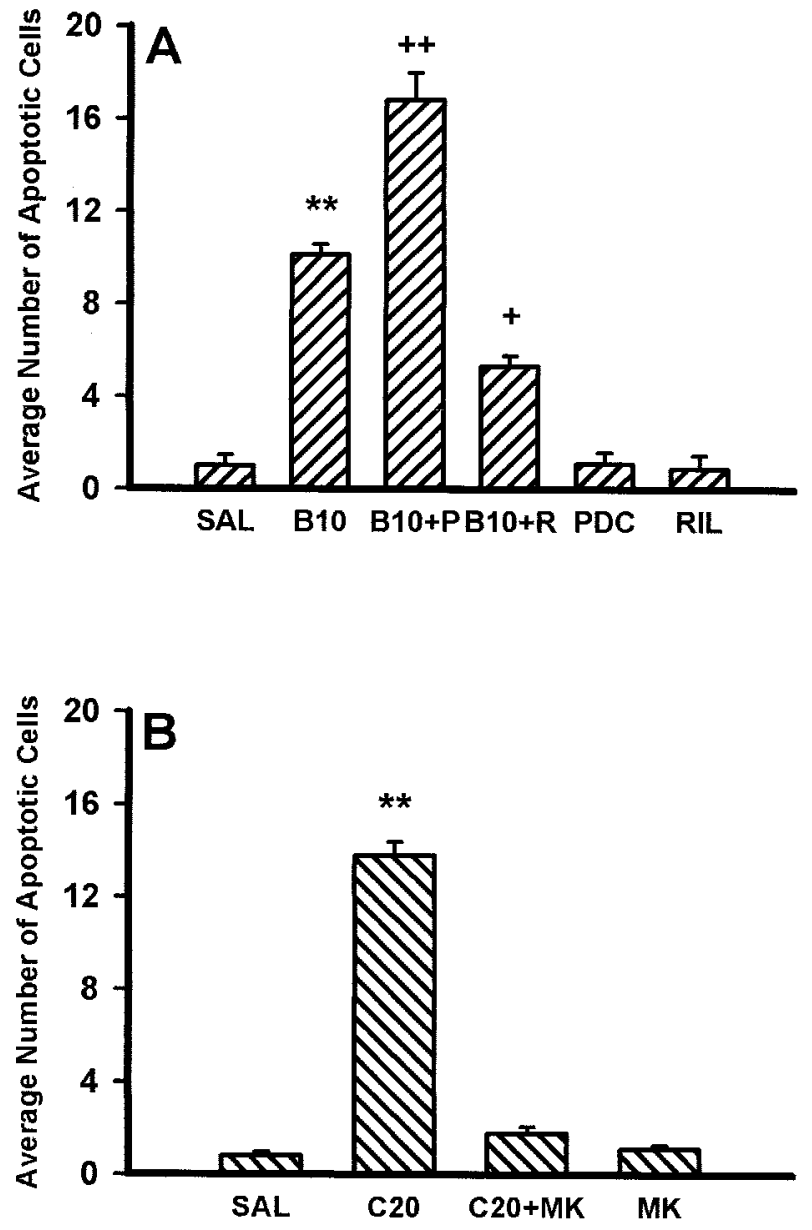

Figure 5. Regulation of neuronal apoptosis by the spinal GT and NMDAR activity. $A$, Coadministration of $10 \mu \mathrm{g}$ of morphine and $20 \mu \mathrm{g}$ of PDC $(B 10+P)$ for $7 \mathrm{~d}$ increased the total number of apoptotic cells. Conversely, coadministration of $10 \mu \mathrm{g}$ of morphine and $20 \mu \mathrm{g}$ of riluzole $(B 10+R)$ for $7 \mathrm{~d}$ decreased the number of apoptotic cells. The administration of PDC or riluzole $(R I L)$ alone for $7 \mathrm{~d}$ did not affect apoptosis. $B$, Coadministration of $20 \mathrm{nmol} \cdot \mu \mathrm{l}^{-1} \cdot \mathrm{hr}^{-1}$ morphine and 1 $\mathrm{nmol} \cdot \mu \mathrm{l}^{-1} \cdot \mathrm{hr}^{-1}$ MK-801 $(C 20+M K)$ for $7 \mathrm{~d}$ effectively blocked the induction of apoptotic cells. The $1 \mathrm{nmol} \cdot \mu \mathrm{l}^{-1} \cdot \mathrm{hr}^{-1} \mathrm{MK}-801$ infusion alone $(M K)$ did not induce apoptosis. ${ }^{*} p<0.01$, compared with the corresponding saline group; ${ }^{+} p<0.05$; and ${ }^{++} p<0.01$, compared with the morphine-alone group.

that caspases, possibly caspase-3, contribute to the induction of neuronal apoptosis that is in part responsible for the development of morphine tolerance and the associated increase in nociceptive sensitivity.

\section{DISCUSSION}

The CNS effects of opioids are overwhelmingly inhibitory, and tolerance to opioid analgesia develops after its prolonged administration. Our findings indicate that prolonged exposure to morphine, but not an acute morphine treatment, also induces apoptotic cell death in spinal cord dorsal horn regions critically involved in opioid analgesia, which contributes, at least in part, to the behavioral manifestation of morphine tolerance. A large number of these apoptotic cells are likely to be GABAergic neurons. As such, there is an associated increase in nociceptive heat sensitivity in rats showing neuronal apoptosis. Mechanistically, the spinal glutamatergic activity and the NMDAR play an
A

$$
\text { Caspase-3 Bax Bcl-2 }
$$
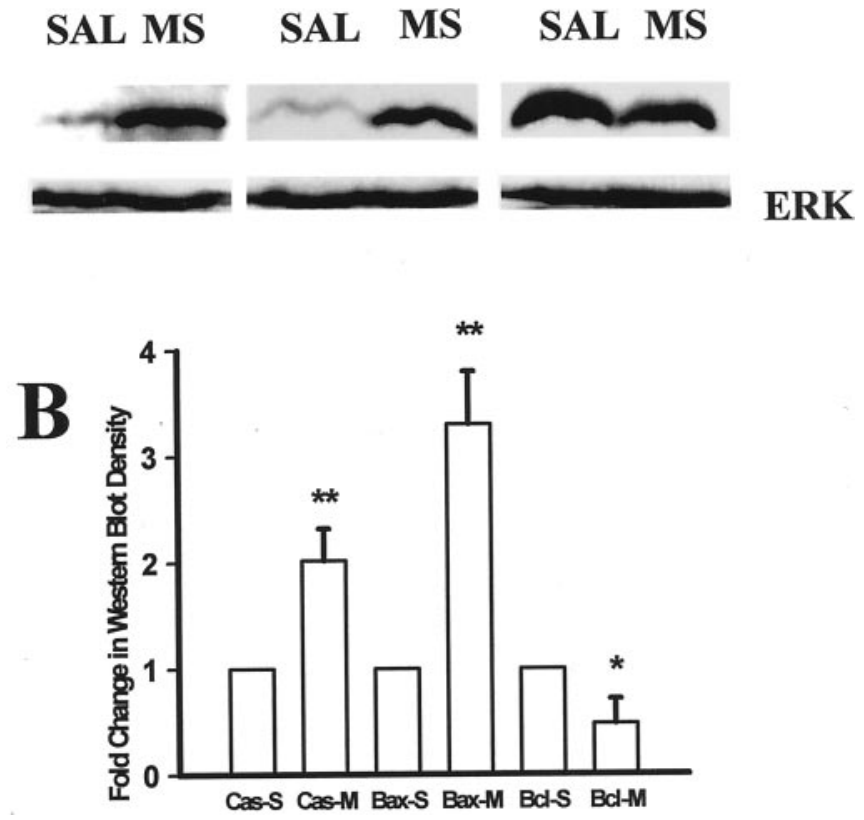

Figure 6. Morphine-induced changes in intracellular caspase-3, Bax, and Bcl-2. $A$, Western blots illustrate upregulation of the proapoptotic caspase-3 $(32 \mathrm{kDa})$ and $\mathrm{Bax}(21 \mathrm{kDa})$ proteins and downregulation of the antiapoptotic $\mathrm{Bcl}-2$ protein $(26 \mathrm{kDa})$ in rats receiving repeated $20 \mu \mathrm{g}$ morphine $(M S)$ twice daily for $7 \mathrm{~d}$ compared with the corresponding saline $(S A L)$ group. $E R K$ is for the protein-loading control. A quantitatively similar upregulation of caspase-3 also was observed when the cleaved caspase- 3 antibody ( $19 \mathrm{kDa}$ ) was used. $B$, The statistical analysis showed differences in the gray density from Western blot bands [caspase-3 (Cas), Bax, and Bcl-2 $(B c l)]$ between saline $(S)$ and morphine $(M)$ treatment. ${ }^{*} p<0.05$; ${ }^{* *} p<0.01$, compared with the corresponding saline group.

important role in morphine-induced neuronal apoptosis and the proapoptotic pathway (Bax and possibly caspase-3) is likely to be an intracellular mediator for the induction of neuronal apoptosis in association with the development of morphine tolerance. These results suggest that prolonged exposure to an opioid such as morphine could lead to two seemingly unrelated consequences, pharmacological tolerance and neuronal excitotoxicity in the form of apoptotic cell death.

\section{Possible mechanisms of morphine-induced neuronal apoptosis}

The present data demonstrate that both morphine tolerance and the associated neuronal apoptosis share a common cellular mechanism at least in part mediated by the NMDAR, because MK-801 blocked both tolerance and apoptosis. This is consistent with the previous observations indicating that (1) NMDA and $\mu$-opioid receptors coexist in single neurons within CNS regions, including the spinal cord (Gracy et al., 1997; Keniston et al., 1998; Commons et al., 1999; Wang et al., 1999); and (2) activation of NMDARs can be facilitated via PKC in neurons treated with an exogenous $\mu$-opioid agonist such as morphine (Chen and Huang, 1991). In addition, our data indicate that the spinal GT activity plays a regulatory role in the cellular mechanisms of morphineinduced neuronal apoptosis. This finding is in agreement with the 

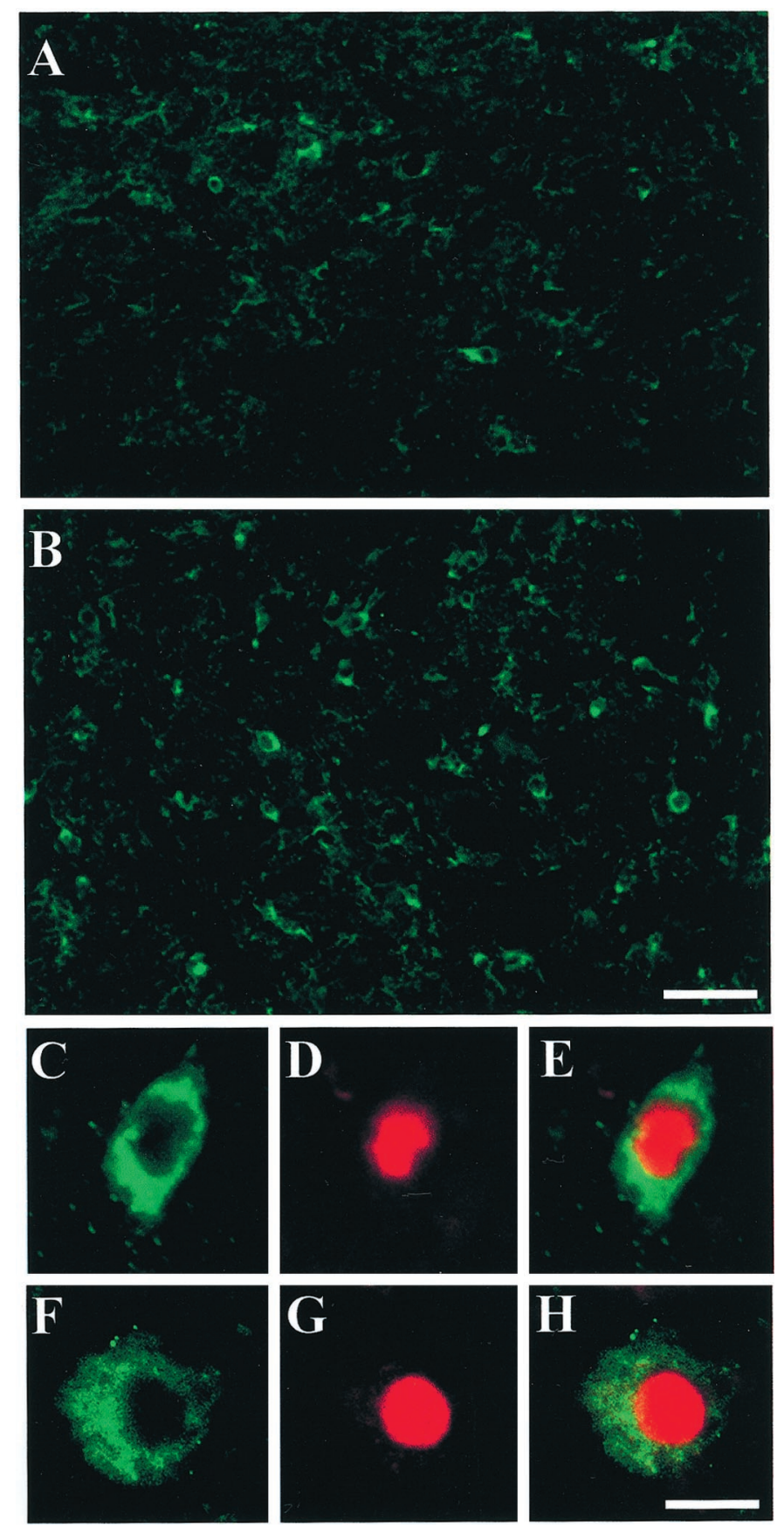

Figure 7. Colocalization of caspase-3 or Bax with the TUNEL staining. $A, B$, The increase in caspase- 3 staining $(B)$ was primarily shown in the superficial dorsal horn of rats receiving a $7 \mathrm{~d}$ intrathecal administration (twice daily) of $20 \mu \mathrm{g}$ of morphine compared with the saline control $(A)$. $C-E$, The caspase-3 (green, cytosol) staining was colocalized with the TUNEL staining (red, nuclear) as shown in $E$ (merged). $F-H$, The Bax (green, cytosol) staining also was colocalized with the TUNEL staining (red) as shown in $H$ (merged). In both cases, the photomicrographs were selected from the same group of rats treated with $20 \mu \mathrm{g}$ of morphine twice daily for $7 \mathrm{~d}$. Scale bars: $A, B, 50 \mu \mathrm{m} ; C-H, 10 \mu \mathrm{m}$.

data showing reduced GT expression after exposure to opioids in both cortical cell cultures (Thorlin et al., 1998) and brain regions (Ozawa et al., 2001), and such a reduction in GT expression could modulate the development of morphine tolerance (Nakagawa et al., 2001). Indeed, changes in the GT activity have been shown to regulate synaptic glutamate availability (Semba and Wakuta,
1998; Mennerick et al., 1999; Jabaudon et al., 2000; Vorwerk et al., 2000), although a process that might change glutamate availability at the synaptic level may not necessarily increase the gross regional glutamate content (Jhamandas et al., 1996).

The findings from this and previous studies suggest that prolonged exposure to a $\mu$-opioid such as morphine can lead to two cellular processes within the same neuron (Chen and Huang, 1991; Mao et al. 1995c), with the involvement of a neural circuit (Zeitz et al., 2002), or both. These two processes include enhanced NMDAR excitability (NMDAR priming) and increased synaptic glutamate availability in the spinal cord dorsal horn (Fig. 9). As described previously (Mao et al., 1994, 1995b; Mayer et al., 1999), the enhanced NMDAR excitability in response to an opioid may be mediated via activation of PKC (Chen and Huang, 1991; Mao et al. 1995c). PKC activation would facilitate, directly or indirectly, the removal of the $\mathrm{Mg}^{2+}$ blockade from the NMDAR-Ca ${ }^{2+}$ channel site (Chen and Huang, 1992; Woolf and Salter, 2000), regulate NMDAR trafficking and gating (Lan et al., 2001), or both, thereby increasing the probability of NMDAR activation. The exact PKC isoform contributing to this process remains uncertain, although $\mathrm{PKC} \gamma$ has been suggested to be at least partially involved (Mao et al. 1995c; Narita et al., 2001; Zeitz et al., 2002). On the other hand, changes in the spinal GT activity after opioid administration may increase the availability of synaptic glutamate as discussed above. Conceivably, enhanced NMDAR excitability coupled with increased synaptic glutamate availability makes the activation of regional NMDARs possible even in the presence of an overwhelmingly inhibitory opioid effect (Mao et al., 1994, 1995b).

Activation of NMDARs would, in turn, initiate intracellular pathways of apoptotic cell death. Indeed, it has been suggested that multiple intracellular mechanisms may be involved in NMDAR-mediated apoptotic changes. In particular, there may be changes in intracellular proapoptotic elements such as Bax and caspase- 3 and antiapoptotic elements such as Bcl-2 in response to NMDAR activation (Du et al., 1997; Tenneti et al., 1998; Allen et al., 1999; Springer et al., 1999; Kwong and Lam, 2000; Nath et al., 2000; Puka-Sundvall et al., 2000; Qin et al., 2000; Tenneti and Lipton, 2000; Bachis et al., 2001; Chan et al., 2001). Recently, chronic morphine treatment has been shown to induce upregulation of the proapoptotic Fas receptor and downregulation of Bcl-2 in the rat brain (Boronat et al., 2001). In the present study, prolonged morphine administration induced upregulation of Bax and caspase- 3 and downregulation of Bcl-2. Importantly, the upregulation of caspase- 3 and Bax was inhibited when morphine was coadministered with the noncompetitive NMDAR antagonist MK-801, supporting a link between NMDAR activation and intracellular changes of caspase- 3 and Bax in response to a prolonged morphine administration. Moreover, similar to the prevention by MK-801 of morphine-induced neuronal apoptosis, inhibition of the spinal caspase-like activity also blocked the induction of morphine-induced neuronal apoptosis. Together, our findings suggest an opioid-induced neurotoxic mechanism that is regulated by the spinal glutamatergic activity and NMDARs as well as the caspase-mediated intracellular apoptotic pathway (Fig. 9).

\section{Functional relation to opioid tolerance and the associated abnormal pain sensitivity}

Opioids are known to induce in vitro apoptosis in multiple cell lines, including neuronal cells (Maneckjee and Minna, 1994; Heusch and Maneckjee, 1999; Singhal et al., 1999; Diao et al., 

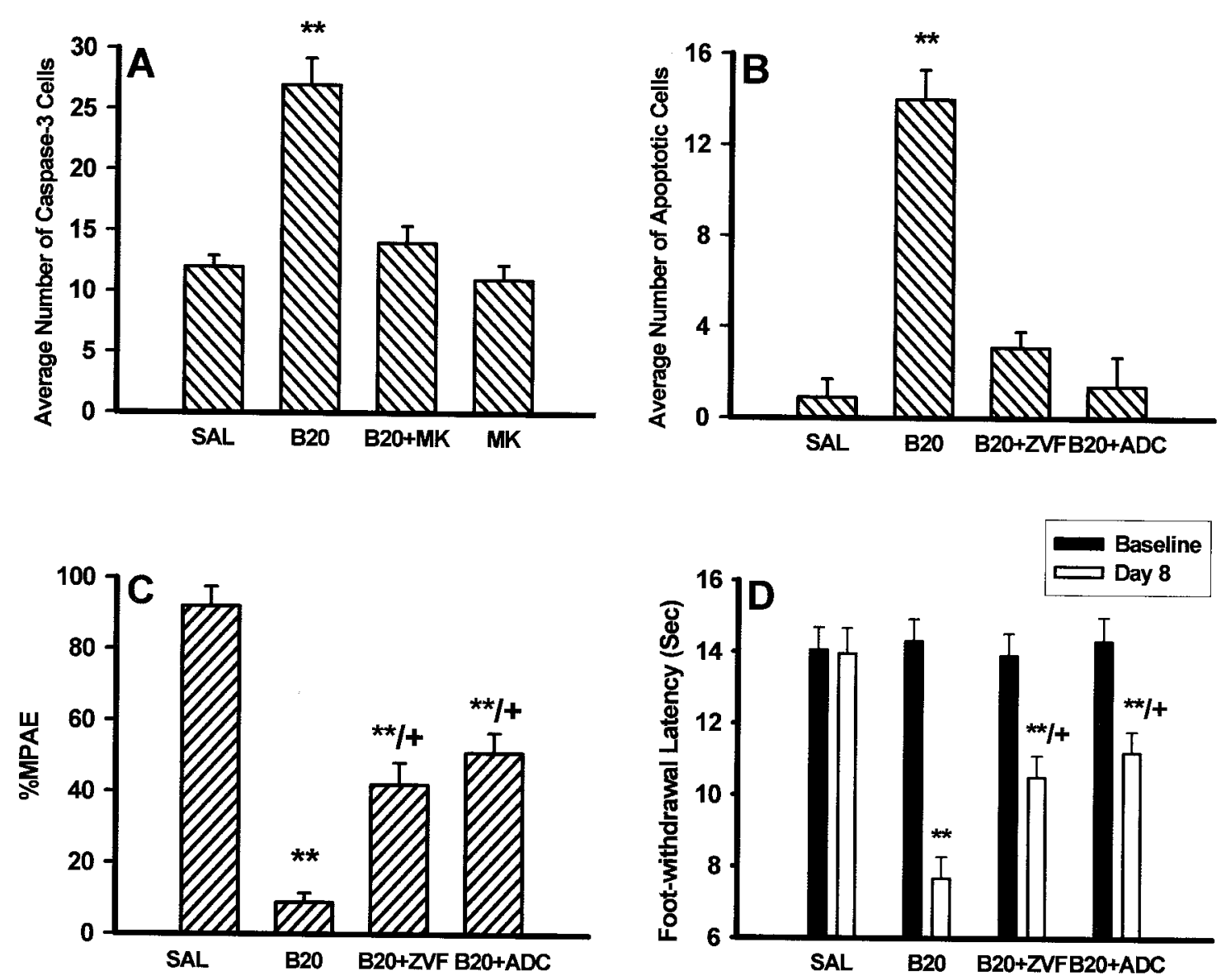

Figure 8. Effects of the inhibition of caspases on apoptosis and morphine tolerance. $A, B$, The caspase-3-positive cells were increased in rats receiving a $7 \mathrm{~d}$ intrathecal administration (twice daily) of $20 \mu \mathrm{g}$ of morphine $(B 20)$ compared with the saline control $(S A L)$. The increase in caspase-3-positive cells was blocked in rats receiving $20 \mu \mathrm{g}$ of morphine and $10 \mathrm{nmol}$ of MK-801 $(B 20+M K)$ twice daily for $7 \mathrm{~d}$. MK-801 alone $(M K)$ did not affect the baseline of caspase-3-positive cells. Coadministration of $20 \mu \mathrm{g}$ of morphine with $5 \mu \mathrm{g}$ of either Z-VAD-FMK (B20+ZVF) or AC-DEVD-CHO $(B 20+A D C)$ for $7 \mathrm{~d}$ nearly abolished morphine-induced apoptosis. $C, D$, Coadministration of $20 \mu \mathrm{g}$ of morphine with $5 \mu \mathrm{g}$ of either Z-VAD-FMK or AC-DEVD-CHO for $7 \mathrm{~d}$ also partially prevented the development of morphine tolerance and the increase in nociceptive heat sensitivity when tested on day $8 .{ }^{* *} p<0.01$, compared with the saline control; ${ }^{+} p<0.05$, compared with the morphine-alone group $(A-C)$ or the baseline value of the same group $(D)$.

2000; Kugawa et al., 2000; Yoshida et al., 2000). This opioidinduced apoptosis is considered beneficial for fighting malignant tumor cells. In this experimental paradigm, however, in vivo apoptosis occurred in the spinal cord dorsal horn regions critically involved in opioid analgesia in response to clinically relevant morphine analgesic doses given through a common administration route. Because a large portion of apoptotic cells are likely to be GABAergic neurons within the superficial spinal cord dorsal horn, this morphine-induced neuronal excitotoxic process could lead to changes in spinal neural circuits involved in pain and pain modulation, thereby enhancing pain sensitivity by means of spinal disinhibition.

Indeed, signs of abnormal pain such as hyperalgesia have been observed both in animals exposed to opioids such as morphine and heroin (Mao et al., 1994; Ossipov et al., 1995; Wegert et al., 1997; Vanderah et al., 2000; Celerier et al., 2001) and in human subjects undergoing acute or chronic opioid therapy (Sjogren et al., 1993; Devulder, 1997). This is further supported by the present data showing increased nociceptive heat sensitivity in rats with neuronal apoptosis, which was potentiated by the GT inhibitor PDC. However, both apoptosis and increased nociceptive heat sensitivity were prevented by the noncompetitive NMDAR antagonist MK-801. Of significance to note is that the present data indicate a functional link between morphine-induced apoptosis, morphine tolerance, and tolerance-related abnormal nociceptive sensitivity, because inhibition of morphine-induced apoptosis by the relatively selective caspase-3 inhibitor AC-DEVD$\mathrm{CHO}$ partially prevented morphine tolerance and the associated increase in nociceptive heat sensitivity. An interesting distinction between the effects of MK-801 and AC-DEVD-CHO is that both tolerance and increased nociceptive sensitivity were effectively prevented by MK-801 but incompletely prevented by ACDEVD-CHO, suggesting that morphine-induced neuronal apoptosis may contribute to the cellular mechanisms of morphine tolerance and the associated increase in nociceptive sensitivity.

\section{Clinical implications}

The present findings suggest important implications in chronic opioid therapy. First, if neuronal apoptosis is a part of the neural mechanisms of opioid tolerance, tolerance to opioids would be less likely to fully recover and more likely to be exacerbated in the subsequent opioid therapy in the clinical setting. Second, opioidinduced apoptosis would be of particular concern in cancer pain and chronic nonmalignant pain treatment that often requires 


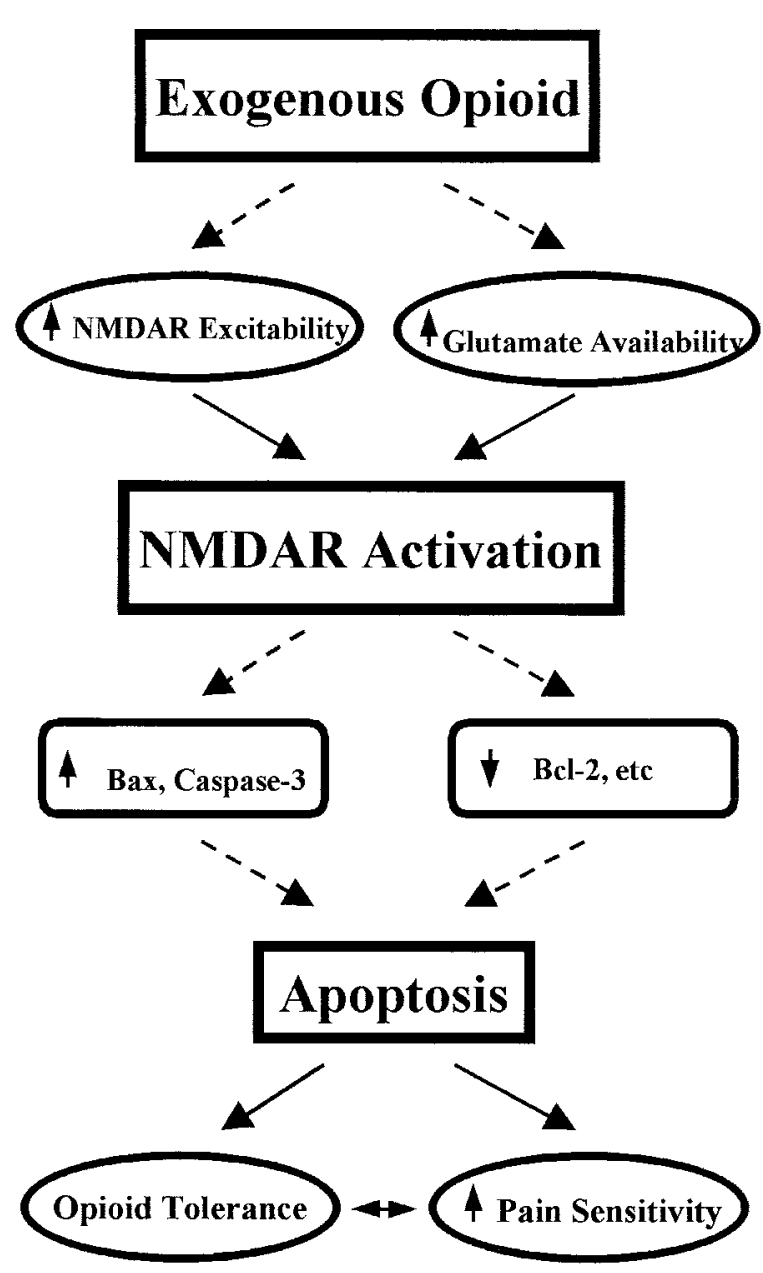

Figure 9. Possible mechanisms of opioid-induced neuronal apoptosis. The data from both previous and present studies suggest that NMDAR activation may be initiated after prolonged exposure to a $\mu$-opioid agonist such as morphine by means of increased NMDAR excitability and regional glutamate availability. NMDAR activation would enhance intracellular positive apoptosis regulators such as Bax and caspases and decrease negative apoptosis regulators such as $\mathrm{Bcl}-2$. The resultant apoptosis contributes, at least in part, to the neural mechanisms of opioid tolerance and the associated increase in abnormal pain sensitivity. Dashed lines indicate the involvement of additional intermittent steps.

prolonged use of opioids. A loss of opioid analgesic efficacy attributable to tolerance in combination with enhanced pain sensitivity secondary to neurotoxicity would compromise the outcome of chronic opioid therapy and more importantly would lead to persistent changes in the neural circuits involved in pain and pain modulation. This may be reflected as repeated dose escalation during opioid therapy regardless of disease progression and an intractable chronic pain state refractory to opioid treatment, because opioid therapy itself may be the driving force for such a condition. Third, such a consequence could be further exacerbated in neuropathic pain treatment with opioids, because neuropathic pain itself may be associated with the CNS neurotoxic changes (Mao et al. 1992b, 1997; Kawamura et al., 1997; Whiteside and Munglani, 2001). As indicated by the present data, however, blockade of NMDARs, modulation of the spinal GT activity, inhibition of intracellular proapoptotic elements, or a combination of the three during opioid therapy may help prevent the development of opioid-induced neurotoxic changes.
Another clinical implication of the present findings is related to the field of substance abuse. Neurobehavioral changes indicative of drug addiction can be seen after exposure to a substance of abuse such as cocaine, alcohol, or heroin. A common feature of such neurobehavioral changes is the difficulty of rehabilitation, with a high tendency of relapse. Critically, activation of NMDARs has been extensively implicated in the neural mechanisms of such neurobehavioral changes (De Montis et al., 1992; Cebere et al., 1999; Churchill et al., 1999; Cornish et al., 1999; Huber et al., 2001), and neuronal apoptosis has indeed been observed in the prenatal and early postnatal stages of animals exposed to a substance of abuse (Nassogne et al., 1997; He et al., 1999). Therefore, a corollary of our findings showing opioidinduced apoptosis in adult rats is that persistent CNS changes in the form of apoptosis may be triggered by a substance of abuse and may contribute to clinical features of substance abuse.

In summary, we found that a subgroup of neurons, as well as glial cells, primarily located in the superficial laminas of the spinal cord dorsal horn and likely to be inhibitory GABAergic neurons, undergo the NMDAR- and caspase-mediated apoptotic process in association with the development of morphine tolerance. These findings may have significant clinical implications in relation to chronic opioid therapy and substance abuse.

\section{REFERENCES}

Akil H, Mayer DJ (1972) Antagonization of stimulation produced analgesia by p-CPA, a serotonin synthesis inhibitor. Brain Res 44:692-697.

Allen JW, Knoblach SM, Faden AI (1999) Combined mechanica trauma and metabolic impairment in vitro induces NMDA receptordependent neuronal cell death and caspase-3-dependent apoptosis. FASEB J 13:1857-1882.

Azbill RD, Mu X, Srpinger JE (2000) Riluzole increases high-affinity glutamate uptake in rat spinal cord synaptosome. Brain Res 871:175-180.

Baba N, Koji T, Itho M, Akio M (1999) Reciprocal changes in the expression of $\mathrm{Bcl}-2$ and $\mathrm{Bax}$ in hypoglossal nucleus after axotomy in adult rats: possible involvement in the induction of neuronal cell death. Brain Res 827:122-129.

Bachis A, Colangelo AM, Vicini S, Doe PP, Bernardi A, Brooker G, Mocchetti I (2001) Interleukin-10 prevents glutamate-mediated cerebellar granule cell death by blocking caspase-3-like activity. J Neurosci 21:3104-3112.

Boronat MA, Garcia-Fuster MJ, Garcia-Sevilla JA (2001) Chronic morphine induces up-regulation of the pro-apoptotic Fas receptor and down-regulation of the anti-apoptotic $\mathrm{Bcl}-2$ oncoprotein in rat brain Br J Pharmacol 134:1263-1270.

Catania MV, Hollingsworth Z, Penney JB, Young AB (1993) Phospholipase A2 modulates different subtypes of excitatory amino acid receptors: autoradiographic evidence. J Neurochem 60:236-245.

Cebere A, Cebers G, Liljequist S (1999) Enhancement of NMDAinduced functional responses without NMDA receptor changes following chronic ethanol exposure in granule cells. Naunyn Schmiedebergs Arch Pharmacol 360:623-632.

Celerier E, Laulin JP, Corcuff JB, Le Moal M, Simonnet G (2001) Progressive enhancement of delayed hyperalgesia induced by repeated heroin administration: a sensitization process. J Neurosci 21:4074-4080.

Chan YM, Wu W, Yip HK, So KF, Oppenheim RW (2001) Caspase inhibitors promote the survival of avulsed spinal motoneurons in neonatal rats. NeuroReport 12:541-545.

Chen L, Huang LYM (1991) Sustained potentiation of NMDA receptormediated glutamate responses through activation of protein kinase $\mathrm{C}$ by a $\mu$-opioid. Neuron 7:319-326.

Chen L, Huang LYM (1992) Protein kinase C reduces $\mathrm{Mg}^{2+}$ block of NMDA-receptor channels as a mechanism of modulation. Nature 356:521-523.

Cheramy A, Barbeito L, Godeheu G, Glowinski J (1992) Riluzole inhibits the release of glutamate in the caudate nucleus of the cat in vivo. Neurosci Lett 147:209-212.

Churchill L, Swanson CJ, Urbina M, Kalivas PW (1999) Repeated cocaine alters glutamate receptor subunit levels in the nucleus accumbens and ventral tegmental area of rats that develop behavioral sensitization. J Neurochem 72:2397-2403.

Commons KG, Van Bockstaele EJ, Pfaff NW (1999) Frequent colocalization of Mu opioid and NMDA-type glutamate receptors at postsynaptic sites in periaqueductal gray neurons. J Comp Neurol 408:549-559. 
Cornish JL, Duffy P, Kalivas PW (1999) A role of nucleus accumbens glutamate transmission in the relapse to cocaine-seeking behaviors. Neuroscience 93:1359-1367.

D'Amour FE, Smith DL (1941) A method for determining loss of pain sensation. J Pharmacol Exp Ther 72:74-79.

De Montis MG, Devoto P, Meloni D, Ganbarana C, Giorgi G, Tangliamonte A (1992) NMDA receptor inhibition prevents tolerance to cocaine. Pharmacol Biochem Behav 42:179-182.

Devulder J (1997) Hyperalgesia induced by high-dose intrathecal sufentanil in neuropathic pain. J Neurosurg Anesthesiol 9:146-148.

Diao CT, Li L, Lau SY, Wong TM, Wong NS (2000) Kappa-opioid receptor potentiates apoptosis via a phospholipase $\mathrm{C}$ pathway in the CNE2 human epithelial tumor cell line. Biochem Biophys Acta 1499:49-62.

Doble A (1996) The pharmacology and mechanism of action of riluzole. Neurology 47:S233-S241.

Du Y, Bales KR, Dodel RC, Hamilton-Byrd E, Horn JW, Czilli DL, Simmons LK, Ni B, Paul SM (1997) Activation of a caspase-e-related cysteine protease is required in glutamate-mediated apoptosis of cultured cerebellar granule neurons. Proc Natl Acad Sci USA 94:11657-11662.

Dunbar SA, Pulai IJ (1998) Repetitive opioid abstinence causes progressive hyperalgesia sensitive to $N$-methyl-D-aspartate receptor blockade in the rat. J Pharmacol Exp Ther 284:678-686.

Elliott K, Minami N, Kolesnikov YA, Pasternak GW, Inturrisi CE (1994) The NMDA receptor antagonists, LY274614 and MK-801, and the nitric oxide synthase inhibitor, NG-nitro-L-arginine, attenuate analgesic tolerance to the mu-opioid morphine but not to kappa opioids. Pain 56:69-75.

Gavrieli Y, Sherman Y, Ben-Saaon SA (1992) Identification of programmed cell death in situ via specific labeling of nuclear DNA fragmentation. J Cell Biol 119:493-501.

Gracy KN, Svingos AL, Pickel VM (1997) Dual ultrastructural localization of mu-opioid receptors and NMDA-type glutamate receptors in the shell of the rat nucleus accumbens. J Neurosci 17:4839-4848.

Granados-Soto V, Kalcheva I, Hua X, Newton A, Yaksh TL (2000) Spinal PKC activity and expression: role in tolerance produced by continuous spinal morphine infusion. Pain 85:395-404.

Hara A, Yoshimi N, Hirose Y, Ino N, Tanaka T, Mori H (1995) DNA fragmentation in granular cells of human cerebellum following global ischemia. Brain Res 697:247-250.

Hara A, Niwa M, Nakashima M, Iwai T, Uematsu T, Yoshimi N, Mori H (1998) Protective effect of apoptosis-inhibitory agent, $N$-tosyl-Lphenyllalanyl chloromethyl ketone against ischemia-induced hippocampal neuronal damage. J Cereb Blood Flow Metab 18:819-823.

Hargreaves K, Dubner R, Brown F, Flores C, Joris J (1988) A new and sensitive method for measuring thermal nociception in cutaneous hyperalgesia. Pain 32:77-88.

He N, Song Z, Lidow MS (1999) Cocaine induces cell death within the primate fetal cerebral wall. Neuropathol Appl Neurobiol 6:504-512.

Heusch WL, Maneckjee R (1999) Effects of bombesin on methadoneinduced apoptosis of human lung cancer cells. Cancer Lett 136:177-185

Huber JD, Darling SF, Park K, Soliman KF (2001) The role of NMDA receptors in neonatal cocaine-induced neurotoxicity. Pharmacol Biochem Behav 69:451-459.

Ibuki T, Dunbar SA, Yaksh TL (1997) Effect of transient naloxone antagonism on tolerance development in rats receiving continuous spinal morphine infusion. Pain 70:125-132.

Jabaudon D, Scanziani M, Gahwiler BH, Gerber U (2000) Acute decrease in net glutamate uptake during energy deprivation. Proc Natl Acad Sci USA 97:5610-5615.

Jhamandas KH, Marsala M, Ibuki T, Yaksh TL (1996) Spinal amino acid release and precipitated withdrawal in rats chronically infused with spinal morphine. J Neurosci 16:2758-2766.

Ji RR, Zhang Q, Law PY, Low HH, Elde R, Hokfelt T (1995) Expression of mu-, delta-, and kappa-opioid receptor-like immunoreactivities in rat dorsal root ganglia after carrageenan-induced inflammation. J Neurosci 15:8156-8166.

Kawamura T, Akira T, Watanabe H, Kagitani Y (1997) Prostaglandin E1 prevents apoptotic cell death in superficial dorsal horn of rat spinal cord. Neuropharmacology 36:1023-1030.

Keniston L, Mao J, Price DD, Lu J, Mayer DJ (1998) Co-localization of $\mu$-opioid and $N$-methyl-D-aspartate receptors to single neurons in the spinal cord dorsal horn of the adult rat. Soc Neurosci Abstr 24:390.

Kugawa F, Ueno A, Aoki M (2000) Apoptosis of NG108-5 cells induced by buprenorphine hydrochloride occurs via the caspase-3 pathway. Biol Pharmacol Bull 23:930-935.

Kwong JM, Lam TT (2000) N-Methyl-D-aspartate (NMDA) induced apoptosis in adult rabbit retinas. Exp Eye Res 71:437-444

Lan JY, Skeberdis VA, Jover T, Grooms SY, Lin Y, Araneda RC, Zheng X, Bennett MVL, Zukin RS (2001) Protein kinase C modulates NMDA receptor trafficking and gating. Nat Neurosci 4:382-390.

Lievens JC, Bernal F, Forni C, Mahy N, Kerkerian-Le Goff L (2000) Characterization of striatal lesions produced by glutamate uptake al- teration: cell death, reactive gliosis, and changes in GLT-1 and GADD45 mRNA expression. Glia 29:222-232.

Lo AC, Houenou LJ, Oppenheim RW (1995) Apoptosis in the nervous system: morphological features, methods, pathology, and prevention. Arch Histol Cytol 58:139-149.

Maneckjee R, Minna JD (1994) Opioids induce while nicotine suppresses apoptosis in human lung cancer cells. Cell Growth Differ 5:1033-1040.

Mao J (1999) NMDA and opioid receptors: their interactions in antinociception, tolerance and neuroplasticity. Brain Res Brain Res Rev 30:289-304.

Mao J, Price DD, Mayer DJ, Hayes RL (1992a) Pain-related increases in spinal cord membrane-bound protein kinase $\mathrm{C}$ following periphera nerve injury. Brain Res 588:144-149.

Mao J, Mayer DJ, Hayes RL, Lu J, Price DD (1992b) Differential roles of NMDA and non-NMDA receptor activation in induction and maintenance of thermal hyperalgesia in rats with painful peripheral mononeuropathy. Brain Res 598:271-278.

Mao J, Mayer DJ, Hayes RL, Price DD (1993) Spatial patterns of increased spinal cord membrane-bound protein kinase $\mathrm{C}$ and their relation to increases in 14C-2-deoxyglucose metabolic activity in rats with painful peripheral mononeuropathy. J Neurophysiol 70:470-481.

Mao J, Price DD, Mayer DJ (1994) Thermal hyperalgesia in association with the development of morphine tolerance in rats: roles of excitatory amino acid receptors and protein kinase C. J Neurosci 14:2301-2312.

Mao J, Price DD, Mayer DJ (1995a) Experimental mononeuropathy reduces the antinociceptive effects of morphine: implications for common intracellular mechanisms involved in morphine tolerance and neuropathic pain. Pain 61:353-364.

Mao J, Price DD, Mayer DJ (1995b) Mechanisms of hyperalgesia and opiate tolerance: a current view of their possible interactions. Pain 62:259-274

Mao J, Price DD, Phillips LL, Lu J, Mayer DJ (1995c) Increases in protein kinase $\mathrm{C}$ gamma immunoreactivity in the spinal cord of rats associated with tolerance to the analgesic effects of morphine. Brain Res 677:257-267.

Mao J, Price DD, Zhu J, Lu J, Mayer DJ (1997) The inhibition of nitric oxide-activated poly(ADP-ribose) synthetase attenuates transsynaptic alteration of spinal cord dorsal horn neurons and neuropathic pain in the rat. Pain 72:355-366.

Marek P, Ben Eliyahu S, Gold M, Liebeskind JC (1991a) Excitatory amino acid antagonists (kynurenic acid and MK-801) attenuate the development of morphine tolerance in the rat. Brain Res 547:77-81.

Marek P, Ben Eliyahu S, Vaccarino AL, Liebeskind JC (1991b) Delayed application of MK-801 attenuates development of morphine tolerance in rats. Brain Res 558:163-165.

Matthews CC, Zielke HR, Wollack JB, Fishman PS (2000) Enzymatic degradation protects from glutamate excitotoxicity. J Neurochem 75:1045-1052.

Mayer DJ, Mao J, Price DD (1995) The development of morphine tolerance and dependence is associated with translocation of protein kinase C. Pain 61:365-374.

Mayer DJ, Mao J, Holt J, Price DD (1999) Cellular mechanisms of neuropathic pain, morphine tolerance, and their interactions. Proc Natl Acad Sci USA 96:7731-7736.

Mennerick S, Shen W, Xu W, Benz A, Tanaka K, Shimamoto K, Isenb KE, Krause JE, Zorumski CF (1999) Substrate turnover by transporters curtails synaptic glutamate transients. J Neurosci 19:9242-9251.

Molander C, Xu Q, Grant G (1984) The cytoarchitectonic organization of the spinal cord in the rat. I. The lower thoracic and lumbosacral cord. J Comp Neurol 230:133-141.

Moncada C, Lekieffre D, Arvin B, Meldrum B (1992) Effect of NO synthase inhibition on NMDA- and ischaemia-induced hippocampal lesions. NeuroReport 3:530-532.

Mullen RJ, Buck CR, Smith AM (1992) NeuN, a neuronal specific nuclear protein in vertebrates. Development 116:201-211.

Nakagawa T, Ozawa T, Shige K, Yamamoto R, Minami M, Satoh M (2001) Inhibition of morphine tolerance and dependence by MS-153, a glutamate transporter activator. Eur J Pharmacol 419:39-45.

Narita M, Mizoguchi H, Kampine JP, Tseng LF (1996) Role of protein kinase $\mathrm{C}$ in desensitization of spinal delta-opioid-mediated antinociception in the mouse. Br J Pharmacol 118:1829-1835.

Narita M, Mizoguchi H, Nagase H, Suzuki T, Tseng LF (2001) Involvement of spinal protein kinase C-gamma in the attenuation of opioidmu-receptor-mediated G-protein activation after chronic intrathecal administration of [D-Ala2, $N$-MePhe4, Gly-O15]enkephalin. J Neurosci 21:3715-3720.

Nassogne MC, Louahed J, Evrard P, Courtoy PJ (1997) Cocaine induces apoptosis in cortical neurons of fetal mice. J Neurochem 68:2442-2450.

Nath R, Scott M, Nadimpalli R, Gupta R, Wang KK (2000) Activation of apoptosis-linked caspase(s) in NMDA-injured brain in neonatal rats. Neurochem Int 36:119-126.

Ossipov MH, Lopez Y, Nichols ML, Bian D, Porreca F (1995) The loss of antinociceptive efficacy of spinal morphine in rats with nerve ligation 
injury is prevented by reducing spinal afferent drive. Neurosci Lett 199:87-90.

Ozawa T, Nakagawa T, Shige K, Minami M, Satoh M (2001) Changes in the expression of glial glutamate transporters in the rat brain accompanied with morphine dependence and naloxone-precipitated withdrawal. Brain Res 905:254-258.

Price DD (1988) Psychological and neural mechanisms of pain. New York: Raven.

Puka-Sundvall M, Hallin U, Zhu C, Wang X, Karlsson JO, Blomgren K, Hagberg H (2000) NMDA blockade attenuates caspase-3 activation and DNA fragmentation after neonatal hypoxia-ischemia. NeuroReport 11:2833-2836.

Qin ZH, Wang Y, Chasea TN (2000) A caspase-3-like protease is involved in NF-kB activation induced by stimulation of $N$-methyl-Daspartate receptors in rat striatum. Brain Res Mol Brain Res 80:111-122

Robinson MB, Dowd LA (1997) Heterogeneity and functional properties of subtypes of sodium-dependent glutamate transporters in the mammalian central nervous system. Adv Pharmacol 37:69-115.

Rothman SM, Olney JW (1986) Glutamate and the pathophysiology of hypoxic-ischemic brain damage. Ann Neurol 19:105-111.

Semba J, Wakuta MS (1998) Regional differences in the effects of glutamate uptake inhibitor trans-pyrrolidine-2,4-bicarboxylic acid on extracellular amino acids and dopamine in rat brain: an in vivo microdialysis study. Gen Pharmacol 31:399-404.

Singhal PC, Kapasi AA, Reddy K, Franki N, Gibbons N, Ding G (1999) Morphine promotes apoptosis in Jurkat cells. J Leukoc Biol 66:650-658

Sjogren P, Josson T, Jesen NH, Drenck NE, Jensen TS (1993) Hyperalgesia and myoclonus in terminal cancer patients treated with continuous intravenous morphine. Pain 55:93-97.

Springer JE, Azbill RD, Knapp PE (1999) Activation of the caspase-3 apoptotic cascade in traumatic spinal cord injury. Nat Med 5:943-946.

Swan JH, Meldrum BS (1990) Protection by NMDA antagonists against selective cell loss following transient ischaemia. J Cereb Blood Flow Metab 10:343-351.

Tenneti L, Lipton SA (2000) Involvement of activated caspase-3-like proteases in $N$-methyl-D-aspartate-induced apoptosis in cerebrocortical neurons. J Neurochem 74:134-142.
Tenneti L, D'Emilia DM, Troy CM, Lipton SA (1998) Role of caspases in $N$-methyl-D-aspartate-induced apoptosis in cerebrocortical neurons. J Neurochem 71:946-959.

Thorlin T, Roginski RS, Choudhury K, Nilsson M, Ronnback L, Hansson E, Eriksson PS (1998) Regulation of the glial glutamate transporter GLT-1 by glutamate and delta-opioid receptor stimulation. FEBS Lett 425:453-459.

Trujillo KA, Akil H (1991) Inhibition of morphine tolerance and dependence by the NMDA receptor antagonist MK-801. Science 251:85-87.

Vanderah TW, Gardell LR, Burgess SE, Ibrahim M, Dogrul A, Zhong CM, Malan TP, Ossipov MH, Lai J, Porreca F (2000) Dynorphin promotes abnormal pain and spinal cord opioid antinociceptive tolerance. J Neurosci 20:7074-7079.

Vorwerk CK, Naskar R, Schuettauf F, Quinto K, Zurakowski D, Gochenauer G, Robinson, Mackler SA, Dreyer EB (2000) Depression of retinal glutamate transporter function leads to elevated intravitreal glutamate levels and ganglion cell death. Invest Ophthalmol Vis Sci 41:3615-3621.

Wang H, Gracy KN, Pickel VM (1999) $\mu$-Opioid and NMDA-type glutamate receptors are often colocalized in spiny neurons within patches of the caudate-putamen nucleus. J Comp Neurol 412:132-146.

Wegert S, Ossipov MH, Nichols ML, Bian D, Vanderah TW, Malan Jr TP, Porreca F (1997) Differential activities of intrathecal MK-801 or morphine to alter responses to thermal and mechanical stimuli in normal and nerve-injured rats. Pain 71:57-64.

Whiteside GT, Munglani R (2001) Cell death in the superficial dorsal horn in a model of neuropathy. J Neurosci Res 64:168-173.

Woolf CJ, Salter MW (2000) Neuronal plasticity: increasing the gain in pain. Science 288:1765-1769.

Yaksh TL, Rudy TA (1976) Chronic catheterization of the spinal subarachnoid space. Physiol Behav 17:1031-1036.

Yoshida A, Tokuyama S, Iwamura T, Ueda H (2000) Opioid analgesicinduced apoptosis and caspase-independent death in human lung carcinoma A549 cells. Int J Mol Med 6:329-335.

Zeitz KP, Malmberg AB, Gilbert H, Basbaum AI (2002) Reduced development of tolerance to the analgesic effects of morphine and clonidine in PKC $\gamma$ mutant mice. Pain 94:245-253. 